\title{
Contribution of personal weather stations to the observation of deep-convection features near the ground
}

\author{
Marc Mandement and Olivier Caumont \\ CNRM, Université de Toulouse, Météo-France, CNRS, Toulouse, France \\ Correspondence: Marc Mandement (marc.mandement@meteo.fr)
}

Received: 11 July 2019 - Discussion started: 17 July 2019

Revised: 2 December 2019 - Accepted: 12 December 2019 - Published: 24 January 2020

\begin{abstract}
The lack of observations near the surface is often cited as a limiting factor in the observation and prediction of deep convection. Recently, networks of personal weather stations (PWSs) measuring pressure, temperature and humidity in near-real time have been rapidly developing. Even if they suffer from quality issues, their high temporal resolution and their higher spatial density than standard weather station (SWS) networks have aroused interest in using them to observe deep convection. In this study, the PWS contribution to the observation of deep-convection features near the ground is evaluated. Four cases of deep convection in 2018 over France were considered using data from Netatmo, a PWS manufacturer. A fully automatic PWS processing algorithm, including PWS quality control, was developed. After processing, the mean number of observations available increased by a factor of 134 in mean sea level pressure (MSLP), of 11 in temperature and of 14 in relative humidity over the areas of study. Near-surface SWS analyses and analyses comprising standard and personal weather stations (SPWSs) were built. The usefulness of crowdsourced data was proven both objectively and subjectively for deep-convection observation. Objective validations of SWS and SPWS analyses by leave-one-out cross validation (LOOCV) were performed using SWSs as the validation dataset. Over the four cases, LOOCV root-mean-square errors (RMSEs) decreased for all parameters in SPWS analyses compared to SWS analyses. RMSEs decreased by $73 \%$ to $77 \%$ in MSLP, $12 \%$ to $23 \%$ in temperature and $17 \%$ to $21 \%$ in relative humidity. Subjectively, fine-scale structures showed up in SPWS analyses, while being partly, or not at all, visible in SWS observations only. MSLP jumps accompanying squall lines or individual cells were observed as well as wake lows at the rear of these lines. Temperature drops and humidity rises accom-
\end{abstract}

panying most of the storms were observed sooner and at a finer resolution in SPWS analyses than in SWS analyses. The virtual potential temperature was spatialized at an unprecedented spatial resolution. This provided the opportunity for observing cold-pool propagation and secondary convective initiation over areas with high virtual potential temperatures, i.e. favourable locations for near-surface parcel lifting.

\section{Introduction}

The increasing number of connected objects - i.e. with Internet access - which carry meteorological sensors has raised the interest of scientists because they are a supplementary means of observing the atmosphere. Several publications emphasize the high potential of these sensors for the finescale observation of atmospheric phenomena, complementary to traditional sources, given the unprecedented spatiotemporal resolution of the networks constituted by these sensors (Muller et al., 2015; Chapman et al., 2017). These new observations come from smartphones (Overeem et al., 2013; Mass and Madaus, 2014; McNicholas and Mass, 2018a), connected vehicles (Mahoney and O'Sullivan, 2013) or personal weather stations (PWSs hereafter, also called citizen weather stations; Bell et al., 2013), for example. All these studies underline the potential gains in the fine-scale description of the atmosphere near the ground.

Among all meteorological processes, deep convection induces the sharpest variations in pressure, temperature, humidity, wind and rain near the ground. Recognition of deepconvection surface features such as low-level convergence boundaries (Wilson and Schreiber, 1986; Wakimoto and Murphey, 2010), pressure, temperature and humidity fea- 
tures prior to convection (Madaus and Hakim, 2016), as well as tracking their temporal evolution, is deemed crucial for thunderstorm forecasting (Sanders and Doswell, 1995). The prediction of convective initiation location and timing, as well as its evolution, still remain a challenging question. Several studies agree that there is a lack of observations at the surface, which limits the quality of analyses at the convective scale and in turn limits good forecasts of convective events (Stensrud and Fritsch, 1994; Fowle and Roebber, 2003; Snook et al., 2015; Sobash and Stensrud, 2015). Observational studies highlight a need for additional highresolution observations (Adams-Selin and Johnson, 2010; Clark, 2011) because deep convection is often associated with small-scale parameter variations. Additionally, there is a need for validating high-resolution numerical models and verifying their accuracy of deep-convection modelling.

These statements motivated experiments in several fields of meteorology. They have been led using denser observational networks near the ground for the study of a particular storm, for urban climate studies or for hydrological applications. Several assimilation experiments of denser weather station networks or observations made with connected objects have also already been performed. Madaus et al. (2014) performed an hourly assimilation of dense pressure observations from mesonets. Results showed an increase in shortterm forecast accuracy for temperature, wind and pressure near mesoscale phenomena. It was shown that $5 \mathrm{~min}$ assimilation of mesonet data (Sobash and Stensrud, 2015) or nonconventional data (Gasperoni et al., 2018), mostly thermodynamic observations, improved forecasts of convection initiation.

Regarding connected objects, several recent data assimilation experiments focused on smartphone observations (Madaus and Mass, 2017; McNicholas and Mass, 2018b; Hintz et al., 2019). Assimilating smartphone pressure measurements led to some improvements in analyses and shortterm forecasts of surface variables compared to experiments without assimilation of observations. Results shown were strongly sensitive to the quality-control techniques developed in each study. This demonstrates that quantifying the uncertainties associated to these observations, and establishing robust quality-control procedures, is crucial. In parallel, recent work has been done in the urban climate communities that examines phenomena at a city scale, benefiting from a high number of connected objects due to the high population density in cities. Temperature measurements from PWSs have been used to visualize the urban heat island in several western European cities (Wolters and Brandsma, 2012; Chapman et al., 2017; Meier et al., 2017; Napoly et al., 2018). These studies showed that PWSs can provide robust estimates of temperature at a fine scale when measurements are quality-controlled and spatially aggregated. For precipitation, de Vos et al. (2017) showed that dense PWS networks can be used for urban rainfall monitoring in Amsterdam and are able to capture small-scale rainfall dynam- ics well according to a simulation study under ideal measurements conditions (de Vos et al., 2018). Subsequently, a real-time quality-control algorithm of rain gauges produced by Netatmo, a PWS manufacturer, was developed in order to complement traditional networks for operational rainfall monitoring (de Vos et al., 2019). Recently, Clark et al. (2018) showed the benefit of PWS data in the life-cycle observation of a hailstorm that crossed the UK in 2015. The supplementary data in temperature, pressure, wind speed given by the PWSs associated with the UK Met Office network revealed fine-scale structures corresponding to conceptual models of severe thunderstorms. However, the quality-control procedures were not fully automatic, and a manual check of each dataset had to be performed.

The goal of the present study is to evaluate the contribution of PWSs to the existing standard weather station (SWS) network in the observation of deep-convection processes at midlatitudes over France. A fully automatic PWS processing algorithm based on comparisons with SWSs was developed. The features near the ground of isolated storms, multicellular systems or supercell storms are observed, extending the work of Clark et al. (2018), which focused on a sole supercell storm. Observed features of processes responsible for their formation or generated by these systems such as cold pools, gust fronts and sea breeze effects are studied. In order to do so, mean sea level pressure (MSLP), temperature and humidity gridded analyses including PWSs are built. The additional value of these weather stations is objectively evaluated by comparison with reference gridded analyses made only with SWSs. First, in Sect. 2 this study describes interesting convective cases of the spring and summer of 2018 over France. In Sect. 3, a presentation of the different weather station networks used in the study is made. The processing including a quality control of PWSs measurements is detailed in Sect. 4, followed by the validation performed against SWSs in Sect. 5. Then, a focus on some features observed during the different convective cases is made in Sect. 6 to evidence the positive contribution of PWSs.

\section{Overview of the cases}

Four cases are chosen to evaluate the contribution of the PWS network to the observation of deep-convection features near the ground. The considered cases and the periods of time of the cases are indicated in Table 1. The casualties and damage listed in each case come from internal reports of the French emergency management agency (Sécurité Civile), press releases from the prefectures, press releases from the French distribution grid operator (Enedis) and press archives (France 3, Sud Ouest). 
Table 1. Periods of time of each case study.

\begin{tabular}{lllll}
\hline Date & 26 May 2018 & 4 July 2018 & 15 July 2018 & 28 August 2018 \\
\hline Start time (UTC) & $06: 55$ & $05: 55$ & $00: 15$ & $12: 55$ \\
\hline End time (UTC) & $23: 55$ & $21: 55$ & $23: 55$ & $23: 55$ \\
\hline
\end{tabular}

\subsection{May 2018: bow echo over the west of France}

On 26 May 2018 a mid-level low at $500 \mathrm{hPa}$ was located in the Bay of Biscay (Fig. 1). This induced a moderate southerly flux over France: the Bordeaux sounding at 23:00 UTC on 25 May observed a $11 \mathrm{~m} \mathrm{~s}^{-1}$ southerly wind at $500 \mathrm{hPa}$. Two positive (cyclonic) upper-level potential vorticity anomalies circulated during the day in the southerly flux observed near the tropopause (Fig. 2a). At the surface, a shallow pressure low around $1010 \mathrm{hPa}$ in the bay headed north very slowly during the day. Pressure gradients were weak all over the western part of France. Over the south-west of France, the air was mild and humid due to the convective activity that occurred the day before and in the early hours of 26 May. Indeed, a first mesoscale convective system (MCS) evolved mainly on the Atlantic Ocean, its edges affecting the French Atlantic coast from the Basque Country to Brittany between 25 May at 22:00 UTC and 26 May at 16:00 UTC. The Bordeaux 25 May 23:00 UTC sounding, the closest available before the event, exhibited only $416 \mathrm{~J} \mathrm{~kg}^{-1}$ surfacebased convective available potential energy (SBCAPE) and strong $245 \mathrm{~J} \mathrm{~kg}^{-1}$ convective inhibition (CIN) because of the decrease in temperature near the surface due to the diurnal cycle. However it recorded a $1583 \mathrm{~J} \mathrm{~kg}^{-1}$ most-unstable CAPE (MUCAPE) from the lifting of a $435 \mathrm{~m}$ a.g.l. (above ground level) air parcel $\left(25 \mathrm{~J} \mathrm{~kg}^{-1} \mathrm{CIN}\right.$ for this parcel). This shows the presence of unstable levels above the stable nocturnal boundary layer. The sounding observed a moderate 0 $6 \mathrm{~km}$ a.g. $1.16 \mathrm{~m} \mathrm{~s}^{-1}$ wind shear, and the hodograph exhibited a clockwise rotation of the winds in the $0-1 \mathrm{~km}$ a.g.l. layer, resulting in a $69 \mathrm{~m}^{2} \mathrm{~s}^{-2}$ helicity.

At the rear of the first MCS, thunderstorms formed in the north of Spain, west of the Pyrenees, between 06:00 and 08:00 UTC. These cells, advected by the mid-troposphere southern flux, crossed the Pyrenees and headed north towards Bordeaux. A squall-line organization of the thunderstorms appeared at around 10:00 UTC. This MCS transitioned into a bow echo at around 13:00 UTC according to radar reflectivities and crossed the west of France, moving in a south-north orientation from the Bordeaux region towards Normandy and Great Britain (Fig. 3a). The system was still active when it left the French territory at 23:00 UTC. The path followed by the bow echo can be seen west of France in Fig. 4a, marked by the area of high-speed, diverging wind gusts. Also, to the north of the MCS, a severe isolated thunderstorm, identified as a supercell in the radar imagery, developed at around 10:30 UTC and merged with the MCS at around 15:00 UTC.

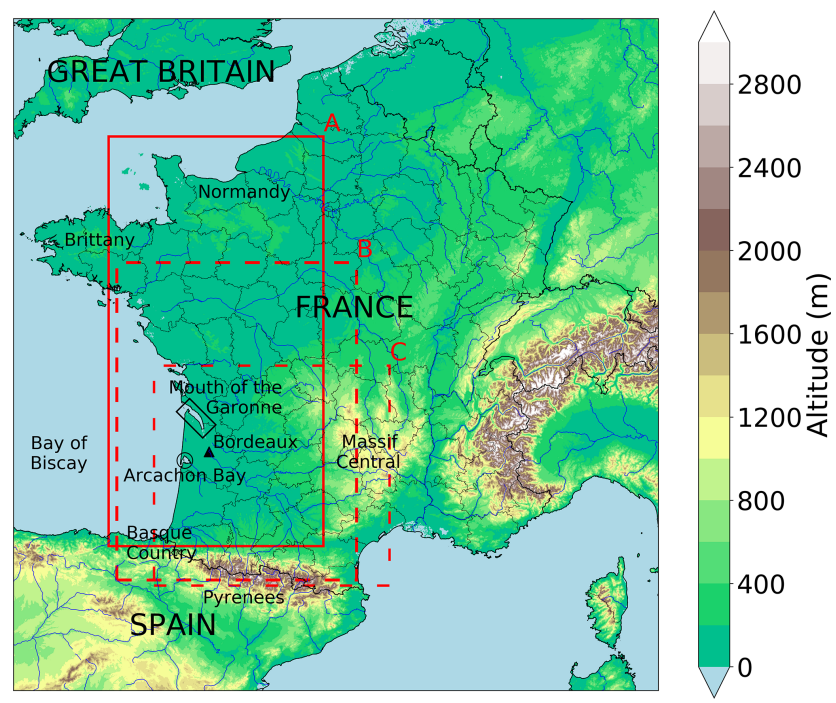

Figure 1. Topographic map of metropolitan France. Domains studied are drawn in red, and locations mentioned are indicated in black. Domain A corresponds to the 26 May case, domain B corresponds to the 28 August case, and domain $\mathrm{C}$ corresponds to the 4 and 15 July cases.

The supercell produced damaging hail up to $4 \mathrm{~cm}$ in diameter and rain up to $22 \mathrm{~mm}$ in $6 \mathrm{~min}$ in the centre of Bordeaux. The bow echo produced mainly strong wind gusts up to $31 \mathrm{~m} \mathrm{~s}^{-1}$ : 13 SWSs recorded gusts higher than $25 \mathrm{~m} \mathrm{~s}^{-1}$, and 4 of them recorded gusts higher than $28 \mathrm{~m} \mathrm{~s}^{-1}$ (Fig. 4a). The two systems resulted in one fatality, 1555 rescue operations and 15000 homes being without power. This produced also local flash floods in Bordeaux and hail damage in the Bordeaux vineyards.

\subsection{July 2018: squall line over the south-west of France}

On 4 July 2018, a mid-level low at $500 \mathrm{hPa}$ was located over the Atlantic Ocean and was extended by a trough across the Iberian Peninsula. The trough moved west towards France during the day, inducing a moderate southwesterly flux at the mid-level over the west of France: the Bordeaux sounding observed a south-westerly $12 \mathrm{~m} \mathrm{~s}^{-1}$ wind at 23:00 UTC on 3 July and south-south-westerly $16 \mathrm{~m} \mathrm{~s}^{-1}$ wind at 11:00 UTC on 4 July. An upper-level potential vorticity anomaly circulated during the afternoon over France at the rear of the convective area and on the left side of a 


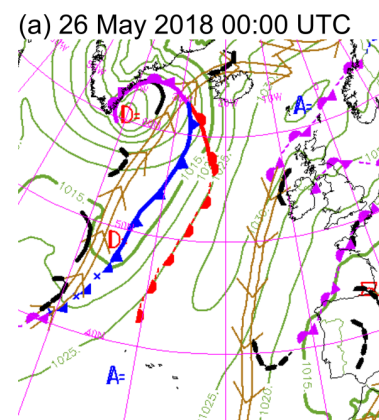

(c) 15 July 2018 12:00 UTC (b) 4 July 2018 12:00 UTC
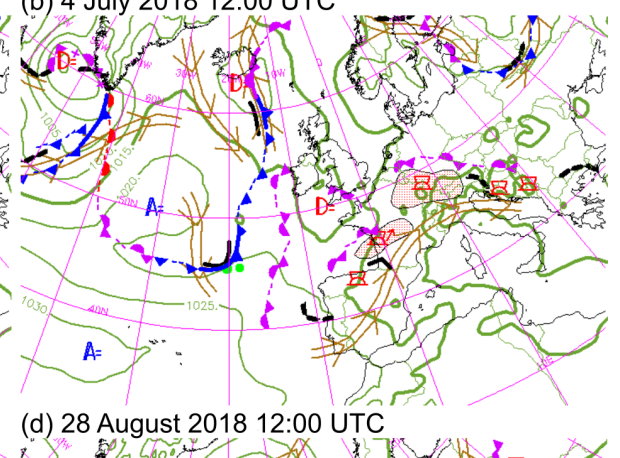

(d) 28 August 2018 12:00 UTC

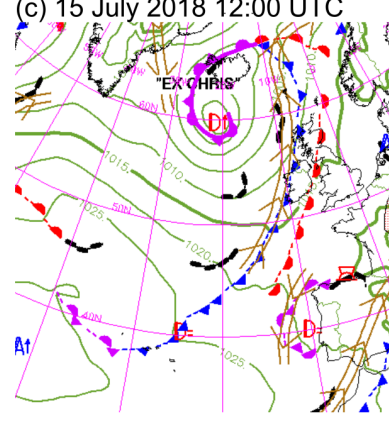

Altitude dynamics

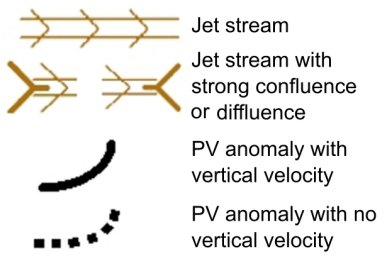

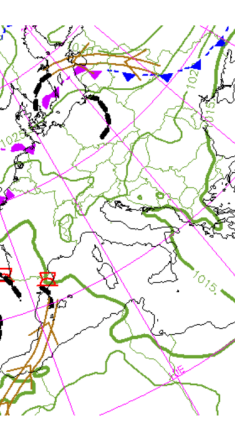

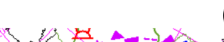

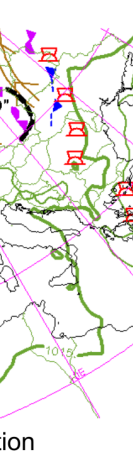

Baroclinic boundaries (false fronts)
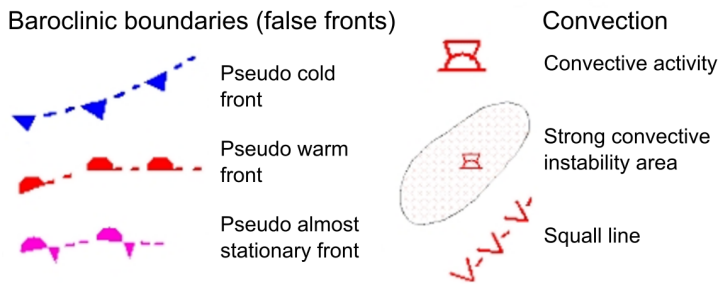

Convection

.

\section{.}




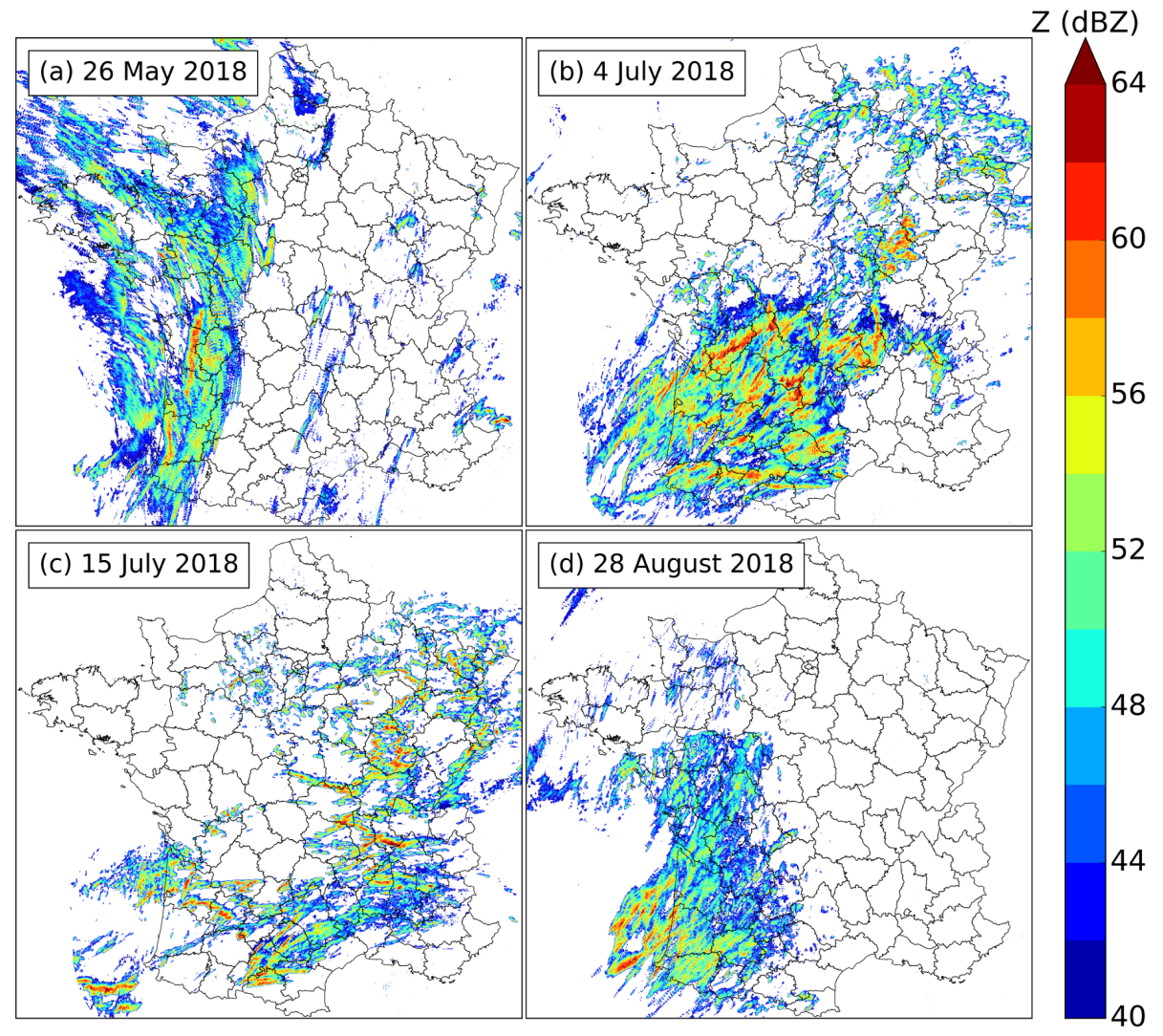

Figure 3. Maximum base reflectivity for each case study: (a) 26 May 2018, (b) 4 July 2018, (c) 15 July 2018 and (d) 28 August 2018.
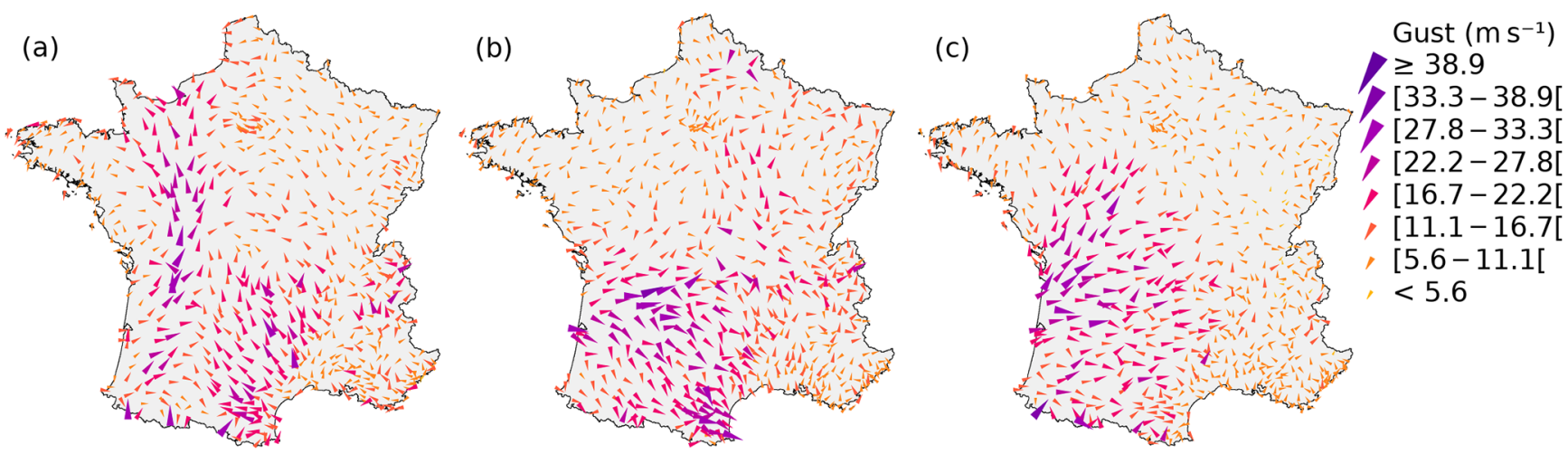

Figure 4. Peak wind gusts measured over metropolitan France (a) on 26 May 2018, (b) on 4 July 2018 and (c) on 28 August 2018. Adapted from Météo-France climatological service.

France during the afternoon in a north-eastward direction (Fig. 2c). At the surface, pressure gradients were weak over France. The sounding of Bordeaux at 11:00 UTC exhibited a SBCAPE of $1790 \mathrm{~J} \mathrm{~kg}^{-1}$ and a CIN of $0 \mathrm{~J} \mathrm{~kg}^{-1}$, showing ideal conditions for the development of surface-based convection. A sea breeze established near the Atlantic shore , and its effects on cloud coverage were visible on satellite images at 12:39 UTC (Fig. 5a). A frontier appeared between the coastal band where temperatures reached 27 to $30^{\circ} \mathrm{C}$ with clear sky and the inland area where temperatures reached 32 to $33.5^{\circ} \mathrm{C}$ and cumulus clouds were developing. Surface observations and satellite images showed the wind convergence due to the breeze moving eastwards between 12:30 and 13:45 UTC. At around 13:10 UTC, towering cumuli turned into cumulonimbi at the south-east of Arcachon Bay (Fig. 5b), where SWSs measured the strongest temperature gradient with a $5{ }^{\circ} \mathrm{C}$ difference in a $40 \mathrm{~km}$ distance. The initiation happened along the wind convergence line. 


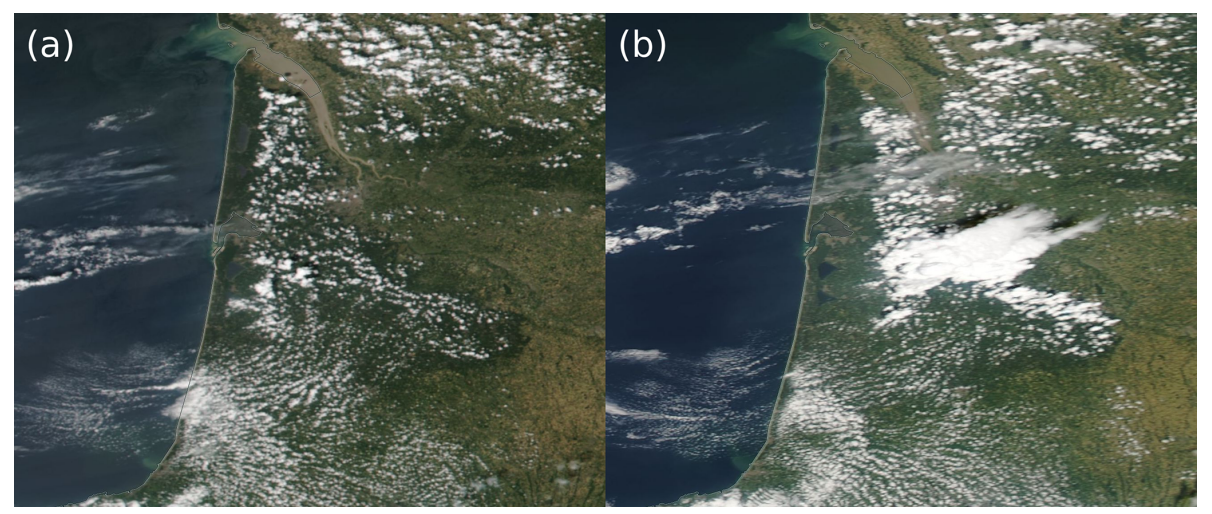

Figure 5. Visible satellite images of convective initiation due to sea breeze convergence on 15 July 2018 taken by (a) Suomi NPP-VIIRS at 12:39 UTC and (b) Aqua MODIS at 13:43 UTC. Images from NASA Worldview.

The first cell triggered secondary cell development west and north of it. Two main cells split and evolved in different directions: the first one headed north-north-east and the other one headed east (Fig. 3c). The cell evolving north-north-east caused high wind gusts up to $34 \mathrm{~m} \mathrm{~s}^{-1}$ at the Bordeaux airport at 15:05 UTC, and the temperature dropped by $15.5^{\circ} \mathrm{C}$ in $23 \mathrm{~min}$. Hail diameters of up to $3 \mathrm{~cm}$ were observed in the Bordeaux region under the thunderstorm. This event caused 84 rescue operations and happened in the context of public gatherings due to the football World Cup Final.

\subsection{August 2018: two squall lines over the west of France}

On 28 August 2018, a mid-level trough at $500 \mathrm{hPa}$ concerned the west of France and moved slightly eastwards during the day, resulting in a south-south-easterly flux. At the surface a low centred north of the Iberian Peninsula deepened during the day (Fig. 2d), helped by a potential vorticity anomaly at upper levels and located to the left of the jet, near a diffluent exit region visible at 18:00 UTC (not shown). The sounding of Bordeaux at 11:00 UTC exhibited a SBCAPE of $1283 \mathrm{~J} \mathrm{~kg}^{-1}$ and a strong CIN of $300 \mathrm{~J} \mathrm{~kg}^{-1}$. The hodograph showed a strong unidirectional $0-6 \mathrm{~km}$ a.g.l. wind shear reaching $25 \mathrm{~m} \mathrm{~s}^{-1}$. Thunderstorms formed south of the low, i.e. over sea and in the north of Spain; they crossed the Pyrenees and the Bay of Biscay between 15:00 and 17:00 UTC and reached French south-western territory between 17:00 and 18:00 UTC as multicellular systems. The northern part of the MCS evolved in squall line between 18:00 and 19:00 UTC, while the southern part formed a second squall line at the rear (Fig. 3d). The two lines generated gusts up to $31 \mathrm{~m} \mathrm{~s}^{-1} ; 15$ SWSs recorded wind gusts higher than $25 \mathrm{~m} \mathrm{~s}^{-1}$, and 6 of them recorded gusts higher than $28 \mathrm{~m} \mathrm{~s}^{-1}$ (Fig. 4c). This resulted in two people being slightly injured, 28000 homes being without power, around 200 rescue operations and nine forest fires being generated by lightning. Hail up to $8 \mathrm{~mm}$ in diameter was reported near the coast.

\section{Datasets}

Two main surface networks are used: automatic SWSs taken as a reference and Netatmo PWSs. To associate surface features to the thunderstorm activity, storms are mainly tracked with the French radar network.

\subsection{SWS network}

SWSs are all automatic Météo-France operational weather stations sampling atmospheric parameters at a time step of $1 \mathrm{~min}$. These weather stations have been installed, maintained and quality-controlled by Météo-France. The requirements in terms of accuracy for Météo-France weather stations are $\pm 0.5^{\circ} \mathrm{C}$ in temperature and $\pm 6 \%$ in relative humidity (Tardieu and Leroy, 2003). They are taken as a reference in this study. The maximum number of weather stations measuring each physical parameter during the cases of 2018 is shown in Table 2. The SWS least-measured parameter over France is surface pressure, with only $19 \%$ of SWSs equipped. The number of humidity and wind sensors equipping SWSs is respectively 3.7 to 3.8 times larger than the number of pressure sensors. Also, there are 5.4 and 5.2 times as many temperature and precipitation sensors as pressure sensors. Additional automatic weather stations, owned by Météo-France or its partners with only $5 \mathrm{~min}, 6 \mathrm{~min}$ or hourly measurements, are not part of the SWS dataset but are used for verification. These represent approximately 800 stations measuring temperature and 250 measuring relative humidity.

\subsection{PWS network}

A PWS dataset made of all Netatmo automatic weather stations available over metropolitan France is used. During the case studies of 2018, a maximum of 44115 different 
Table 2. Maximum available sensors of SWSs and PWSs, i.e. emitting at least one measurement, during the case studies over metropolitan France.

\begin{tabular}{lrr}
\hline $\begin{array}{l}\text { Number of sensors } \\
\text { (\% of stations equipped) }\end{array}$ & SWS & PWS \\
\hline Temperature & $1032(100 \%)$ & $36473(83 \%)$ \\
Precipitation & $1005(97 \%)$ & $11912(27 \%)$ \\
Wind & $736(71 \%)$ & $5763(13 \%)$ \\
Relative humidity & $705(68 \%)$ & $36472(83 \%)$ \\
Surface pressure & $192(19 \%)$ & $42029(95 \%)$ \\
\hline Number of weather stations & 1032 & 44115 \\
\hline
\end{tabular}

PWSs recorded at least one observation which is approximately 15 times the total number of professional automatic weather stations currently available at Météo-France. Among these PWSs, $95 \%$ recorded pressure measurements, $83 \%$ temperature and relative-humidity measurements, $27 \%$ rain measurements, and $13 \%$ wind measurements. On 15 July, for example, PWSs provided a total of 5625137 surface pressure observations, 4837133 temperature observations and 4836843 relative-humidity observations during the case study.

The metadata associated with each station are quite basic: a unique identification number, the latitude, the longitude and the altitude. The altitude of $17 \%$ of PWSs is missing. During the year 2017, the number of PWSs recording at least once in a month increased from around 37800 in January to around 44000 in December, showing the rapid development of this network.

The transmission of data by these PWSs is based on radio waves between outdoor and indoor modules, on Wi-Fi between the indoor module and the personal Internet box, and then on different methods but essentially wires between the personal Internet box and the Internet service provider. At each step, technical failures or user-related shutdowns can occur. In each file transmitted by the PWS's manufacturer, $10 \%$ to $15 \%$ of the total number of PWSs do not provide measurements. This can be due to disconnection between station modules, disconnection of the personal Internet box, or power or Internet outages.

PWS measurements are irregular in time, whereas meteorological networks are usually designed to perform them at regular time steps. The mean time step between two measurements indicated by the manufacturer is $5 \mathrm{~min}$; it may sometimes vary because PWS owners can also perform additional on-demand measurements. However, Netatmo provided, in near-real time, only 10 min time step measurements, which is the minimum time step used in this study. On average, most of the measurements are done at the minutes 5, 15, 25, 35, 45 and 55 of each hour. Also, the mean spacing between PWSs is not regular, whereas the average separation of SWSs is about $30 \mathrm{~km}$. The spatial density of PWSs is highly correlated to the population density (Fig. 6).

\subsection{Radar}

The operational weather radar network between May and August 2018 in metropolitan France is composed of 30 radars; 5 radars in the south of France are S-band radars, 20 are C-band radars and 5 are X-band radars. In this study, the French operational base reflectivity, i.e. measured at the lowest elevation angle of the radar, mosaicked from these 30 radars, is used. It has a $1 \mathrm{~km} \times 1 \mathrm{~km}$ spatial resolution and a 5 min temporal resolution, with reflectivities ranging from -9 to $70 \mathrm{dBZ}$ with a $0.5 \mathrm{dBZ}$ step. For every pixel in the mosaic, the maximum base reflectivity from radars distant by $180 \mathrm{~km}$ or less is taken. If the pixel is distant by more than $180 \mathrm{~km}$ to every radar, the maximum base reflectivity of radars at a distance between 180 and $250 \mathrm{~km}$ is taken. More details on the French radar network are given by Figueras i Ventura and Tabary (2013).

\section{Data processing}

To compare PWS and SWS time series, a linear interpolation of each PWS time series was done at the minutes 5, 15, 25, 35,45 and 55 of each hour because most of the measurements are done at these times. The result is a missing value if the two closest measurements around the interpolation time are separated by a period of $700 \mathrm{~s}$ or more. These interpolated time series are referred to as raw PWS time series.

The inspection of raw PWS time series for all parameters shows major departures compared to SWS time series, which confirms the necessity of a quality control, as already stated in previous studies (Bell et al., 2013; Muller et al., 2015; Meier et al., 2017; Napoly et al., 2018). Measurements provided by PWSs have a lot of uncertainties due to heterogeneous and unknown environmental conditions. The ground type, the direct exposure of PWS sensors to solar radiation or heat sources, the lack of ventilation, the lack of maintenance, or calibration problems can lead to errors. Field tests were realized at Météo-France over $80 \mathrm{~d}$ by comparing three Netatmo PWSs to a reference SWS, including a platinum temperature sensor with an accuracy of $\pm 0.23^{\circ} \mathrm{C}$ between -20 and $40^{\circ} \mathrm{C}$ and a Vaisala HMP 110 humidity sensor with an accuracy of $\pm 2.5 \%$ between 0 and $40^{\circ} \mathrm{C}$. Two white plastic radiation shields naturally ventilated are used: the reference sensors were in a Socrima BM0 1195 model, while the Netatmo outdoor modules were in a larger Socrima BM0 1161. Tests show a median and a $95 \%$ range of errors of about $0{ }^{\circ} \mathrm{C} \pm 0.9{ }^{\circ} \mathrm{C}$ in temperature and $+3 \% \pm 7 \%$ in relative humidity. These tests show the correct quality of temperature and humidity sensors when properly protected but do not give insight into their accuracy without the radiation shield. They show the same diurnal cycle of $\Delta T_{\text {Netatmo-SwS }}$ as 


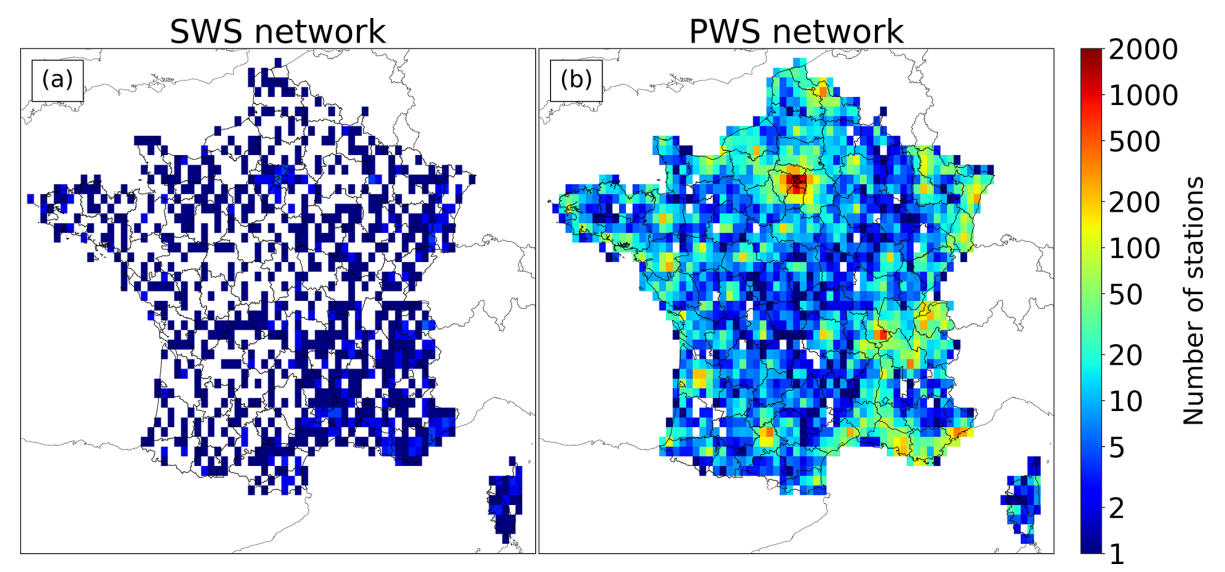

Figure 6. Number of SWSs (a) and PWSs (b) over metropolitan France on 4 July 2018. Observation counts are binned into approximately $0.2^{\circ} \times 0.2^{\circ}$ bins.

the Fig. 2 of Meier et al. (2017) but with a lower amplitude: the median remains in the range $0{ }^{\circ} \mathrm{C} \pm 0.5^{\circ} \mathrm{C}$ for all hours of the day. For pressure, some sources of errors exposed by McNicholas and Mass (2018a) in smartphone pressure sensors apply to PWS pressure sensors because they are similar microelectromechanical systems (MEMS). According to their study, errors result from different response times of sensors to pressure changes, sensor bias, inaccurate metadata or user-related issues (pressurized environments, below or above ground-level PWS locations). The STMicroelectronics MEMS pressure sensor mounted on Netatmo PWS has a $\pm 1 \mathrm{hPa}$ absolute accuracy (Netatmo, 2019).

Because of the uncertainties affecting PWS measurements and the departures observed in comparison to reference measurements, an automatic PWS data processing algorithm was built. This includes a quality control in pressure, temperature and humidity which is designed to be simple and efficient whatever the meteorological situation is. The algorithm is mainly based on comparisons with a quality-controlled reference network as was done by Meier et al. (2017) and Clark et al. (2018). The data processing is performed during the periods of time indicated in Table 1. Cases begin before convection initiation and end after convection dissipation of the storm systems studied over the area of interest. In order to accurately evaluate PWSs and be able to detect abnormal behaviour, calm conditions are necessary for most of the time. Indeed, if storms affect weather stations at each time step, conclusions about the quality of the measurements by comparing it to a reference or close stations may be dubious, given the small scale of some phenomena.

\subsection{Gridding methods}

For temperature, relative humidity, MSLP and surface pressure, all gridded analyses derived from observations are built at a 10 min time step and $0.01^{\circ}$ resolution in latitude and longitude $\left(\approx 1.1 \mathrm{~km} \mathrm{~N}-\mathrm{S}\right.$ and $\approx 0.8 \mathrm{~km} \mathrm{E}-\mathrm{W}$ at $\left.45^{\circ} \mathrm{N}\right)$ by in- terpolating, for each grid point, weather stations available in the vicinity. The gridding method used is the inverse-distance weighting (IDW) with a power factor of 2 . Weather stations too far away from a grid point are not used in the computation.

Every maximum range is a trade-off between the smallest possible range that limits the extrapolation of small-scale features and a larger range keeping enough stations to limit the influence of a single station over the surrounding grid points. For our cases, the maximum distance between every pair of closest SWS sensors is $46 \mathrm{~km}$ for relative humidity and $42 \mathrm{~km}$ for temperature; for the combined network of SWS and PWS after processing (see Sect. 4) it is $28 \mathrm{~km}$ for relative humidity and $21 \mathrm{~km}$ for temperature. These values are lower bounds of the maximum ranges in order to prevent inland grid points from having the value of the closest SWS even if they are not at the same location. For the sake of simplicity, an identical radius is chosen for temperature and relative humidity. Thus, for temperature and relative humidity, SWSs distant by more than $60 \mathrm{~km}$ are not taken into account; this radius is set to $30 \mathrm{~km}$ for PWSs. The choice of $60 \mathrm{~km}$ instead of a $50 \mathrm{~km}$ radius for example is done to take into account more SWSs at each grid point (for a given inland grid point, interpolation uses $9.8 \mathrm{SWSs}$ on average with a $60 \mathrm{~km}$ radius compared to 8.6 SWSs on average with a $50 \mathrm{~km}$ radius for the 26 May case). For MSLP and surface pressure, SWSs distant by more than $100 \mathrm{~km}$ are not taken into account; this radius is also set to $100 \mathrm{~km}$ for PWSs. The radius is larger for pressure because it is the minimum radius for covering the entire metropolitan area of France. This is due to the small number of SWS pressure sensors and because stations with an altitude higher than $750 \mathrm{~m}$ are discarded (see Sect. 4.4). A maximum of 10 SWSs and 30 PWSs are used at each grid point in the IDW, an arbitrary limit set to diminish the program execution time.

MSLP and relative humidity are directly gridded (Fig. 7a; method [1]). For temperature and surface pressure, because they vary strongly with altitude, a linear regression of the 

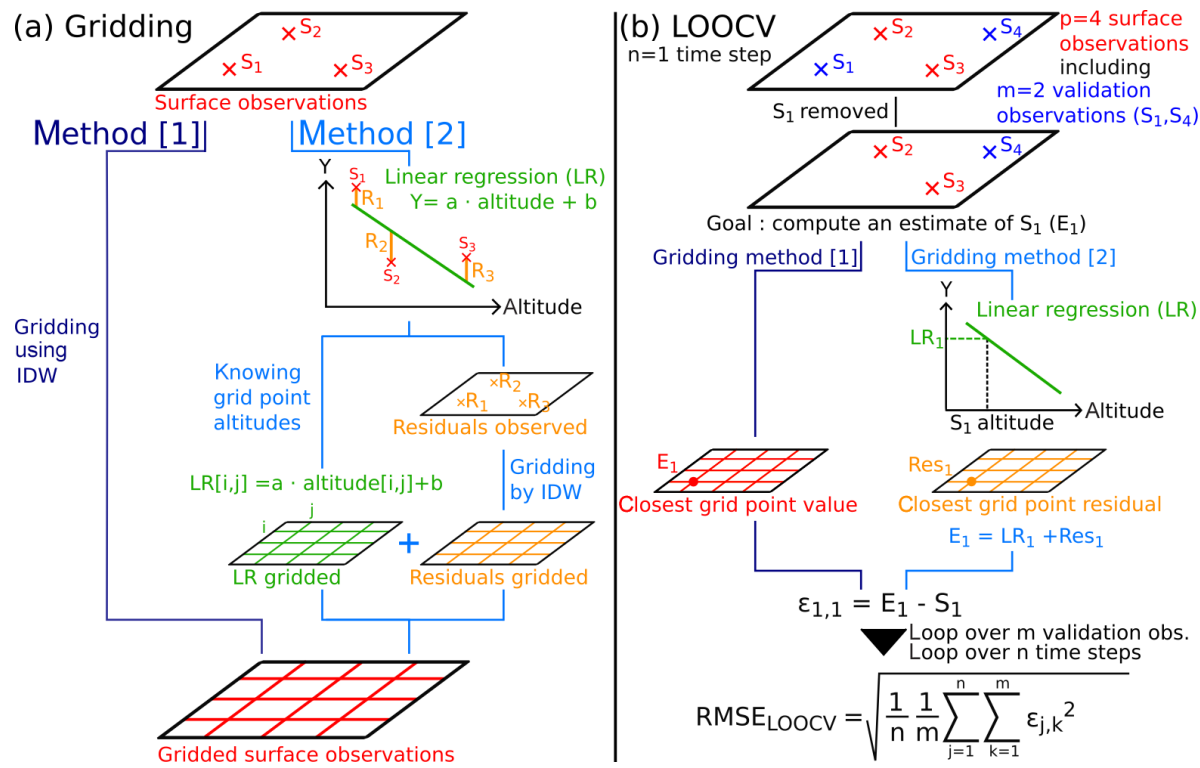

Figure 7. (a) Gridding methods used to build analyses from discrete surface observations. MSLP and relative humidity are gridded using method [1], while temperature and surface pressure are gridded using method [2]. (b) LOOCV algorithm explained through the case of four observations made by four weather stations, including two validation stations during one time step. The complete LOOCV is a loop performed over all time steps $(n)$ and over all validation stations chosen $(m)$. The loop provides an array of errors $\left(\epsilon_{j, k}\right)_{1 \leq j \leq n, 1 \leq k \leq m}$ of dimension $n \times m$, allowing the computation of a RMSE over $n \times m$ observations or a RMSE associated to a validation station only over $n$ observations. If the estimate is equal to the observation, error is equal to zero.

SWS observations used in the gridding with respect to the altitude is performed first. After that, the residuals (i.e. the difference between the values obtained by linear regression and the observations) are gridded as shown in Fig. 7a (method [2]) and then added to the grid derived from the linear regression. For temperature, the linear regression is adapted: to diminish the predominant weight of the low altitude SWSs over the highest SWSs, SWSs are binned in vertical layers of $100 \mathrm{~m}$ height. The mean temperature and the mean altitude of SWSs comprised in each layer are computed. A linear regression is then performed over these vertical layers. This choice was made to be closest to the observed temperature lapse rate rather than using a constant lapse rate.

The reference analyses, called SWS analyses, used in the following sections are built only with SWS data.

\subsection{Computation of PWS MSLP}

Even when the altitude of the Netatmo PWS ( $z$ PWS ) is unknown, the PWS still provides a pressure value. In fact, under the name of pressure, Netatmo provides two different quantities.

- It provides a MSLP (MSLPPwS) computed from the hydrostatic equation assuming a constant $15^{\circ} \mathrm{C}$ temperature and a $0 \%$ relative humidity at sea level if $z$ Pws is known ( $83 \%$ of cases):
$\operatorname{MSLP}_{\mathrm{PWS}}=P\left(1-\frac{\Gamma z_{\mathrm{PWS}}}{T_{0}}\right)^{-\frac{g M}{\Gamma R_{0}}}$,

where $P$ is the surface pressure measured at the PWS (in $\mathrm{hPa}$ ), $T_{0}=288.15 \mathrm{~K}$ is the sea level temperature of the International Civil Aviation Organization (ICAO) standard atmosphere, $\Gamma=0.0065 \mathrm{~K} \mathrm{~m}^{-1}$ is the ICAO environmental lapse rate in the troposphere below $11 \mathrm{~km}, g=9.80665 \mathrm{~m} \mathrm{~s}^{-2}$ is the standard acceleration of gravity, $M=0.0289644 \mathrm{~kg} \mathrm{~mol}^{-1}$ is the molar mass of dry air and $R_{0}=8.31447 \mathrm{~J} \mathrm{~mol}^{-1} \mathrm{~K}^{-1}$ is the ideal gas constant.

- Surface pressure $P$ is provided if $z_{\mathrm{PWS}}$ is unknown (17\% of cases).

To compare MSLPPWs to SWS measurements, it was necessary to recalculate the MSLP. The formula used to calculate the MSLP for SWSs is the one in use at Météo-France and is the same as that used by, for example, Garratt (1984). It takes into account the observed surface temperature and humidity at the weather station:

$$
\begin{aligned}
\mathrm{MSLP} & =P \exp \left(\frac{g M z}{R_{0} \overline{T_{\mathrm{v}}}}\right)=P \exp \left(\frac{\frac{g M}{R_{0}} z}{T_{\mathrm{v}}+\frac{\Gamma}{2} z}\right) \\
& =P \exp \left(\frac{0.03414 z}{T_{\mathrm{v}}+0.00325 z}\right),
\end{aligned}
$$


with $\overline{T_{\mathrm{V}}}$ being the mean virtual temperature in the fictitious air column extending from sea level to the level of the station, which is equal to $T_{\mathrm{v}}+\frac{\Gamma}{2} z$, considering the decrease in the virtual temperature with altitude at a constant lapse rate $\Gamma$ in this column.

The virtual temperature $T_{\mathrm{v}}$ at the weather station is derived from $T$, the $2 \mathrm{~m}$ temperature in kelvin ( $t$ is $T$ in ${ }^{\circ} \mathrm{C}$ ), and the $2 \mathrm{~m}$ water vapour pressure $e=\frac{U}{100} e_{\mathrm{w}}$ (in hPa) where $U$ is the $2 \mathrm{~m}$ relative humidity (in $\%$ ) and $e_{\mathrm{w}}$ is the saturation water vapour pressure (in $\mathrm{hPa}$ ) obtained through the World Meteorological Organization (2014) formula. $T_{\mathrm{v}}$ and $e_{\mathrm{W}}$ are computed as follows:

$$
\begin{gathered}
T_{\mathrm{V}}=\frac{T}{1-\frac{0.378 e}{P}}=\frac{T}{1-\frac{0.378 U e_{\mathrm{w}}}{100 P}}, \\
\text { with } e_{\mathrm{w}}=6.112 \exp \left(\frac{17.62 t}{t+243.12}\right) .
\end{gathered}
$$

$T$ and $U$ are derived from the nearest point of the SWS analyses. The altitude $z$ is equal to zPWS if the difference in altitude is less than $15 \mathrm{~m}$ between $z$ Pws and the Shuttle Radar Topography Mission (SRTM; Farr et al., 2007) digital elevation model (DEM) extracted from Python package "altitude" (de Ruijter, 2016). If the difference is larger than $15 \mathrm{~m}$, the DEM altitude is taken. The value is chosen to keep the benefit of accurate altitudes that may be given by internal GPS of smartphones to the Netatmo mobile application during the PWS set-up process. This results in more accurate altitude when the PWS is located in a small building, for example. Then, comparing metadata to a DEM eliminates altitude errors that may be introduced by users: they may erroneously modify PWS altitude because it is a way to modify the value of PWS pressure.

\subsection{PWS systematic error correction}

The motivation to compare Netatmo measurements to SWS analyses is to eliminate systematic errors. Some of them are due to the PWS itself, such as sensor quality or the impossibility of maintenance by design; some are due to the environmental conditions where the PWS is set up, but some are due to PWS owners who can calibrate sensors as they wish. The mobile-phone application allows users to calibrate the temperature sensor and modify the altitude, which has an influence on pressure. All sensors can be calibrated by personal requests to Netatmo.

For relative humidity, PWS time series are compared to the SWS analyses at the closest grid point. For surface pressure and temperature, because they vary rapidly with altitude, which itself varies rapidly with spatial distance in mountainous regions, the value at the PWS closest grid point may be really different of the actual PWS value. That is why PWS time series are not compared directly to the SWS analyses at the closest grid point. A more precise calculation is performed: the altitude $z$ previously defined, considered to be the closest to the actual PWS altitude, is used in the computation. Residuals time series are taken from the closest grid point residuals. This precise calculation corresponds to SWS analyses having an accurate ground altitude at PWS locations.

For each PWS, the median of the errors between the time series derived from SWS analyses at its location $\left(\boldsymbol{x}_{\boldsymbol{a}}\right)$ and its raw PWS time series $\left(\boldsymbol{x}_{\boldsymbol{r}}\right)$ is obtained. The corrected PWS time series $\left(\boldsymbol{x}_{\mathrm{c}}\right)$ is computed by removing the median of the errors from the raw PWS time series:

$\boldsymbol{x}_{\mathrm{c}}=\boldsymbol{x}_{\mathrm{r}}-\operatorname{med}\left(\boldsymbol{x}_{\mathrm{r}}-\boldsymbol{x}_{\mathrm{a}}\right) \boldsymbol{l}$,

with $\boldsymbol{x}_{\mathrm{c}}, \boldsymbol{x}_{\mathrm{r}}, \boldsymbol{x}_{\mathrm{a}}$ and $\boldsymbol{l}$ column vectors gathering a single PWS time series of dimension $n$, being equal to the number of time steps of a case. Here, $\boldsymbol{l}=\{1, \ldots, 1\}$.

The choice of the median is explained by the observation of large variations in temperature, humidity or pressure due to deep convection. Because of the lower density of the SWS network compared to the PWS network, some of these variations that are actual signals affect the calculation of mean error. Using the median allows for ignoring a major part of these physical deviations while identifying systematic errors affecting PWSs. This procedure is close to the one followed by Madaus et al. (2014), which is performed over periods of several months.

In the following parts, all PWS time series refer to corrected PWS time series. The steps leading to these PWS corrected time series, i.e. the computation of PWS MSLP and the PWS systematic error correction, are referred to as PWS preprocessing.

\subsection{PWS data quality control}

Two common filters are applied to pressure, temperature and humidity. A PWS is removed if it has the same latitude and longitude as another and less than half of the measurements are available. For the computation of MSLP, PWSs with altitude higher than $750 \mathrm{~m}$ are discarded, as recommended by the World Meteorological Organization (2014). Then a last filter is applied in order to discard PWSs that do not provide accurate measurements.

For temperature and relative humidity, the last filter is based on the assumption that the larger the differences between PWS time series and SWS analyses during the case study, and the longer they last, the less confidence is put in PWS measurements. For each PWS, the root-mean-square error (RMSE) of PWSs temperature and relative-humidity time series $\left(\boldsymbol{x}_{\mathrm{c}}\right)$ against time series derived from SWS analyses $\left(\boldsymbol{x}_{\mathrm{a}}\right)$ is computed. It is hereafter called RMSEPWs, with $n$ being the number of time steps:

$\mathrm{RMSE}_{\mathrm{PWS}}=\sqrt{\frac{1}{n} \sum_{j=1}^{n}\left(\boldsymbol{x}_{\mathrm{c}}[j]-\boldsymbol{x}_{\mathrm{a}}[j]\right)^{2}}$. 
The filter eliminates PWSs with RMSEPWs higher than an adaptive threshold called $\mathrm{RMSE}_{\text {thresh }}$ :

RMSEPWS $>$ RMSE $_{\text {thresh }}$.

To determine the RMSE $E_{\text {thresh }}$, an automatic algorithm based on leave-one-out cross validation (LOOCV; see Fig. 7b) was built. Consider $p$ surface stations (PWSs and SWSs) producing observations including $m$ validation stations (SWSs only; $p \geq m$ ). For a given time step $j \in[1 ; n]$, the LOOCV removes one validation observation $k \in[1 ; m]$. Using $p-1$ observations (all except the observation $k$ ), an estimate at the removed observation location $E_{k}(p)$ is computed through the gridding method described in Sect. 4.1. Then, the estimate is compared to the actual observation $S_{k}$, giving an error $\epsilon_{j, k}(p)$ :

$\epsilon_{j, k}(p)=E_{k}(p)-S_{k}$.

The process is reproduced over the $m$ validation stations and the $n$ time steps of the case study, giving an array of $m \times n$ errors, from which the LOOCV RMSE is computed:

$\operatorname{RMSE}_{\operatorname{LoOCV}}(p)=\sqrt{\frac{1}{n} \frac{1}{m} \sum_{j=1}^{n} \sum_{k=1}^{m} \epsilon_{j, k}(p)^{2}}$.

The lower the errors, the closer to the observations the estimates are. Thereby, $\operatorname{RMSE}_{\mathrm{LOOCV}}(p)$ can be chosen as a metric evaluating the accuracy of the $p$ surface stations from which the estimates are built.

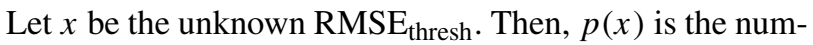
ber of PWSs and SWSs which verify RMSEPWs $\leq x$ ( $m$ is the number of SWSs). The RMSE $E_{\text {thresh }}$ chosen is the $x$ that minimizes $\operatorname{RMSE}_{\mathrm{LOOCV}}(p(x))$ :

$\operatorname{RMSE}_{\text {thresh }}=\operatorname{argmin}{ }_{x} \operatorname{RMSE}_{\text {LOOCV }}(p(x))$.

For large values of $x, p(x)$ tends to the total number of PWSs and SWSs remaining after the two common filters, and so $\operatorname{RMSE}_{\mathrm{LOOCV}}(p(x))$ tends toward large values because almost all PWSs are kept, including those exhibiting abnormal behaviours. For small values of $x, p(x)$ approaches $m$, the number of SWSs, and $\operatorname{RMSE}_{\mathrm{LOOCV}}(p(x))$ approaches quite large values because of the small number of SWSs and their large spacing.

The resulting $\mathrm{RMSE}_{\text {thresh }}$ picked up by the algorithm depends on the case, varying from 1.10 to $1.45^{\circ} \mathrm{C}$ in temperature and from $5.5 \%$ to $7.5 \%$ in relative humidity.

For MSLP and surface pressure, instead of a threshold, PWSs providing suspicious measurements are eliminated one by one by an algorithm. This consists of a LOOCV using SWSs and PWSs as validation stations $(m=p)$ that eliminates one suspicious PWS at each step $s$. PWSs are used in the validation dataset this time because SWS coverage is quite sparse. A one-by-one elimination is possible because only few PWS errors remain after the first three filters in pressure. The suspicious PWS is identified by computing the RMSE associated with all validation stations $k, k \in[1 ; m]$, which is

$\operatorname{RMSE}_{\mathrm{LOOCV}, k}(p)=\sqrt{\frac{1}{n} \sum_{j=1}^{n} \epsilon_{j, k}(p)^{2}}$.

The PWS with the highest $\operatorname{RMSE}_{\mathrm{LOOCV}, k}(p)$ is physically the one which disagrees the most in RMSE with all neighbour PWSs and SWSs during the case study, which is suspicious. This station is eliminated. The algorithm stops when $\operatorname{RMSE}_{\mathrm{LOOCV}}(p)$ increases at step $s+1$ compared to step $s$. Physically, an increase means that a PWS which was in strong agreement with at least one neighbour station (PWS or SWS, called $k^{\prime}$ ) was eliminated at step $s$. At step $s+1$, $k^{\prime}$ captures some physical process (local low or high) but is alone in doing it, and so $\operatorname{RMSE}_{\mathrm{LOOCV}, k^{\prime}}(p)$ increases as well as the RMSE of some PWS around it. As a consequence, the resulting $\operatorname{RMSE}_{\mathrm{LOOCV}}(p)$ taking into account all PWS contributions increases. This algorithm is well fitted for pressure because most of the errors affecting PWSs are uncorrelated, and few PWSs provide erroneous values. This will probably not work for other parameters like temperature, whose errors may be spatially correlated (errors because of direct radiation for example). Each step of quality control in MSLP is detailed in Table 4.

The result of PWS processing is illustrated for temperature in Fig. 8a, for relative humidity in Fig. 8b and for MSLP in Fig. 9. PWS measurements are compared at different time steps to the SWS analyses before and after processing. In terms of temperature (Fig. 8a), the distribution of departures before processing exhibits systematic positive departures with a diurnal cycle. The daily minimum of the median departures is reached in the morning between 08:00 and 10:00 UTC, after sunrise, and the daily maximum is reached in the evening or the night between 17:00 and 06:00 UTC in the 4 July case but also in the other cases not shown. In terms of relative humidity (Fig. 8b), the distribution of departures before processing also exhibits a diurnal cycle, with positive departures during the day and negative departures during the night in all cases. In terms of MSLP (Fig. 9), the distribution of departures before processing seems to exhibit a small diurnal cycle, with departures increasing in the morning and decreasing in the evening. For all parameters, the processing shifts the distribution of departures near zero and strongly decreases the width of the interquartile range of departures. This shows the efficiency of the algorithm in diminishing departures to SWS analyses while keeping features associated with deep convection, as it was designed for (see Sect. 6).

In real time, we do not have access to the complete time series. A variation in the method that could be applied in real time is using time series over a rolling period of the 24 last hours ending at the time of the analysis instead of the time series over a complete event. Then, every $10 \mathrm{~min}$ the automatic processing would be launched for each anal- 
Table 3. Number of PWSs filtered at each step of the quality control in temperature $(T)$ and relative humidity $(U)$ over the area of each case study.

\begin{tabular}{|c|c|c|c|c|c|c|c|c|}
\hline \multirow[t]{2}{*}{ Case study } & \multicolumn{2}{|c|}{26 May 2018} & \multicolumn{2}{|c|}{4 July 2018} & \multicolumn{2}{|c|}{15 July 2018} & \multicolumn{2}{|c|}{28 August 2018} \\
\hline & $T$ & $U$ & $T$ & $U$ & $T$ & $U$ & $T$ & $U$ \\
\hline Number of PWS time series & \multicolumn{2}{|c|}{11372} & \multicolumn{2}{|c|}{5113} & \multicolumn{2}{|c|}{5063} & \multicolumn{2}{|c|}{7347} \\
\hline Same latitude-longitude & \multicolumn{2}{|c|}{100} & \multicolumn{2}{|c|}{37} & \multicolumn{2}{|c|}{32} & \multicolumn{2}{|c|}{48} \\
\hline$>50 \%$ missing values & 615 & 616 & 324 & 326 & 296 & 298 & 448 & 448 \\
\hline $\mathrm{RMSE}_{\mathrm{PWS}}>\mathrm{RMSE}_{\text {thresh }}$ & 6731 & 6242 & 2508 & 2141 & 3103 & 2947 & 4051 & 4735 \\
\hline RMSE $_{\text {thresh }}$ & $1.10^{\circ} \mathrm{C}$ & $6.5 \%$ & $1.40^{\circ} \mathrm{C}$ & $7.5 \%$ & $1.45^{\circ} \mathrm{C}$ & $7.5 \%$ & $1.20^{\circ} \mathrm{C}$ & $5.5 \%$ \\
\hline PWS remaining & 3926 & 4414 & 2244 & 2609 & 1632 & 1786 & 2800 & 2116 \\
\hline$\%$ of total PWS & $35 \%$ & $39 \%$ & $44 \%$ & $51 \%$ & $32 \%$ & $35 \%$ & $38 \%$ & $29 \%$ \\
\hline
\end{tabular}
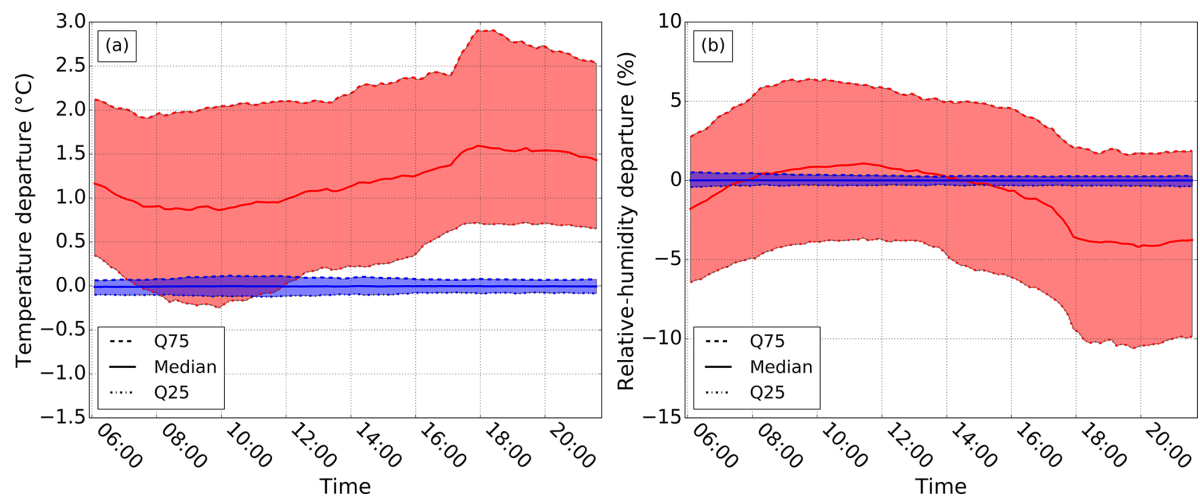

Figure 8. Illustration of the PWS processing in (a) temperature and (b) relative humidity for the 4 July 2018 case. The distribution of departures between PWS measurements and their corresponding SWS analysis values every 10 min is shown with the 25 th quantile $\left(Q_{25}\right)$, the median and the 75th quantile $\left(Q_{75}\right)$. In red are raw PWS time series; in blue are processed PWS time series (time in UTC).

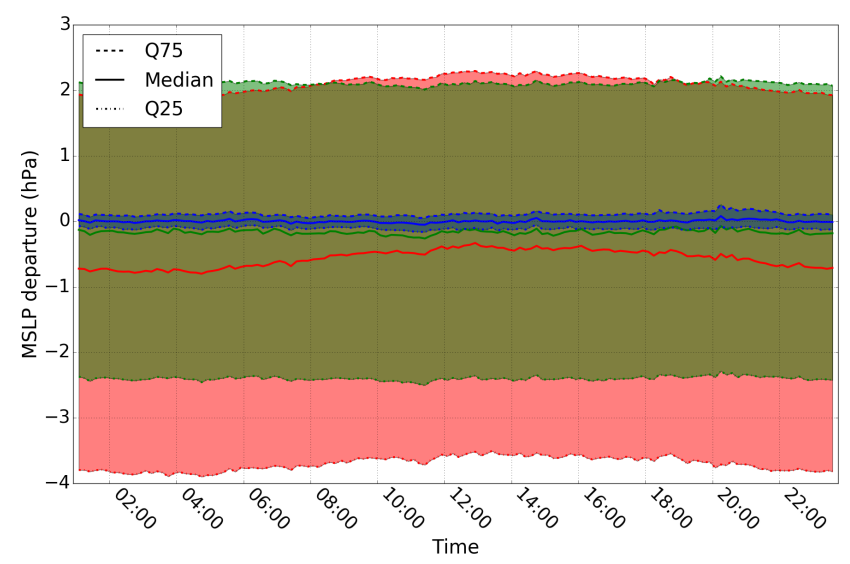

Figure 9. Illustration of the PWS processing in MSLP for the 26 May 2018 case. The distribution of departures between PWS measurements and their corresponding SWS analysis values every 10 min is shown with $Q_{25}$, the median and $Q_{75}$. In red are raw PWS time series, in green are preprocessed PWS time series and in blue are processed PWS time series (time in UTC). ysis produced. This method implies that the algorithm runs in less than $10 \mathrm{~min}$, which is not the case for the current algorithm. It takes around $1 \mathrm{~h}$ to perform the quality control over $24 \mathrm{~h}$ of measurements on a computer with a central processing unit (CPU) with four cores and $16 \mathrm{~GB}$ of randomaccess memory. To increase the processing speed, one or several available computing nodes with 24 cores each could be used because the algorithm is partially parallel. Parts of the algorithm that are still sequential could be parallelized. In addition, the LOOCVs in the quality control could be modified because there are the most time-consuming parts of the algorithm. For temperature and humidity, LOOCVs provide thresholds, and for pressure the LOOCV eliminates a small number of PWSs one by one. Thus, the algorithm at a given time can use the temperature and humidity thresholds as well as the list of PWSs eliminated that were computed by the algorithm launched $1 \mathrm{~h}$ before.

\section{Validation}

After PWS time series were processed, the remaining PWSs were combined to SWSs. This network is called hereafter 
Table 4. Number of PWSs filtered in MSLP at each step of the quality control for each case study.

\begin{tabular}{lrrrr}
\hline Case study & 26 May 2018 & 4 July 2018 & 15 July 2018 & 28 August 2018 \\
\hline Number of PWS time series & 13098 & 5820 & 5783 & 8432 \\
\hline Identical latitude-longitude & 107 & 41 & 36 & 56 \\
$>50 \%$ missing values & 523 & 316 & 277 & 431 \\
Altitude $>750 \mathrm{~m}$ & 7 & 175 & 165 & 105 \\
LOOCV removal algorithm & 155 & 81 & 80 & 65 \\
\hline PWS remaining (\% of PWS time series) & $12306(94 \%)$ & $5207(89 \%)$ & $5225(90 \%)$ & $7775(92 \%)$ \\
\hline
\end{tabular}

the standard and personal weather stations (SPWS) network (Fig. 10), and the gridded fields produced with this network are called SPWS analyses. The additional value of SPWS analyses compared to SWS analyses is evaluated quantitatively in MSLP, temperature and relative humidity. Also, for temperature and relative humidity, in order to evaluate the role of processing in the results obtained, raw PWS time series and SWS time series were combined. The network associated to this dataset is called the SPWS_raw network. It is not done for pressure because the raw dataset blends MSLP and surface pressure as explained in Sect. 4.2.

LOOCVs are performed on SWS, SPWS and SPWS_raw observations ( $p$ observations) and validated on SWS observations ( $m$ observations) included in these datasets. The median of $\epsilon_{j, k}(p)$ over all validation stations $k \in[1 ; m]$ and all time steps $j \in[1 ; n]$ is computed. The $\operatorname{RMSE}_{\text {LOOCV }}(p)$ is also computed and corresponds to the line labelled RMS (root mean square) in the tables. The mean and quartiles of $\epsilon_{j, k}(p)$, not shown in the tables, have also been scrutinized. All experiments are compared to the SWS experiment.

\subsection{MSLP}

In MSLP (Table 5), a decrease ranging from 0.01 to $0.05 \mathrm{hPa}$ in absolute value of the median error is observed in SPWS experiments compared to SWS experiments, depending on the case. The absolute value of the mean error decreases in three cases and remains stable in one case: it is less than $0.02 \mathrm{hPa}$ for all cases in SPWS experiments. A decrease ranging from 0.32 to $0.48 \mathrm{hPa}$ in the interquartile range of errors is observed for all cases in SPWS experiments compared to SWS experiments. Also, a very substantial decrease in RMSE ranging from $73 \%$ to $77 \%$ is observed. These results quantitatively show that adding PWS measurements in observed MSLP analyses strongly improves their accuracy. For MSLP, the number of available observations is multiplied by 134 on average over the four cases with the SPWS network compared to the SWS network.

\subsection{Temperature}

In temperature (Table 6), a positive shift of the median error ranging from 0.73 to $1.39^{\circ} \mathrm{C}$ is observed in SPWS_raw experiments compared to SWS experiments. Bias reaches 0.74 to $1.45^{\circ} \mathrm{C}$, and the increase in RMSE ranges from $41 \%$ to $72 \%$ compared to SWS experiments. These results show the key role of processing: without this step, adding PWSs strongly decreases the quality of analyses.

For SPWS experiments, a decrease ranging from 0.00 to $0.04{ }^{\circ} \mathrm{C}$ in absolute value of the median error is observed compared to SWS experiments, depending on the case. The absolute value of the mean error shows no particular trend and remains less than $0.07^{\circ} \mathrm{C}$ for all cases in SPWS experiments. This indicates that PWSs do not introduce substantial bias or shifts in the temperature distribution. A decrease ranging from 0.06 to $0.22^{\circ} \mathrm{C}$ in the interquartile range of errors is observed for all cases in SPWS experiments compared to SWS experiments. Also, a substantial decrease in RMSE ranging from $12 \%$ to $23 \%$ is observed. These results quantitatively show that adding PWS measurements in temperature analyses improves their accuracies. For temperature, the number of available observations is multiplied by 11 on average over the four cases with the SPWS network compared to the SWS network.

\subsection{Relative humidity}

In relative humidity (Table 7), shifts of the median error ranging from $-3.3 \%$ to $2.7 \%$ are observed in SPWS_raw experiments compared to SWS experiments. Biases reach $-2.3 \%$ to $1.9 \%$, and RMSEs increase from $6 \%$ to $31 \%$ compared to SWS experiments. These results show the key role of processing: without this step, adding PWSs strongly decreases the quality of analyses.

For SPWS experiments, the absolute value of the median error is less than or equal to $0.2 \%$ and the absolute value of the mean error remains less than $0.6 \%$. This indicates that PWSs do not introduce any substantial bias or shifts in the relative-humidity distribution. A decrease ranging from $0.0 \%$ to $1.9 \%$ in the interquartile range of errors is observed for all cases in SPWS experiments compared to SWS experiments. Also, a substantial decrease in RMSE ranging from $17 \%$ to $21 \%$ is observed. These results quantitatively show that adding PWS measurements in relative-humidity analyses improves their accuracies. For relative humidity, the number of available observations is multiplied by 14 on average 


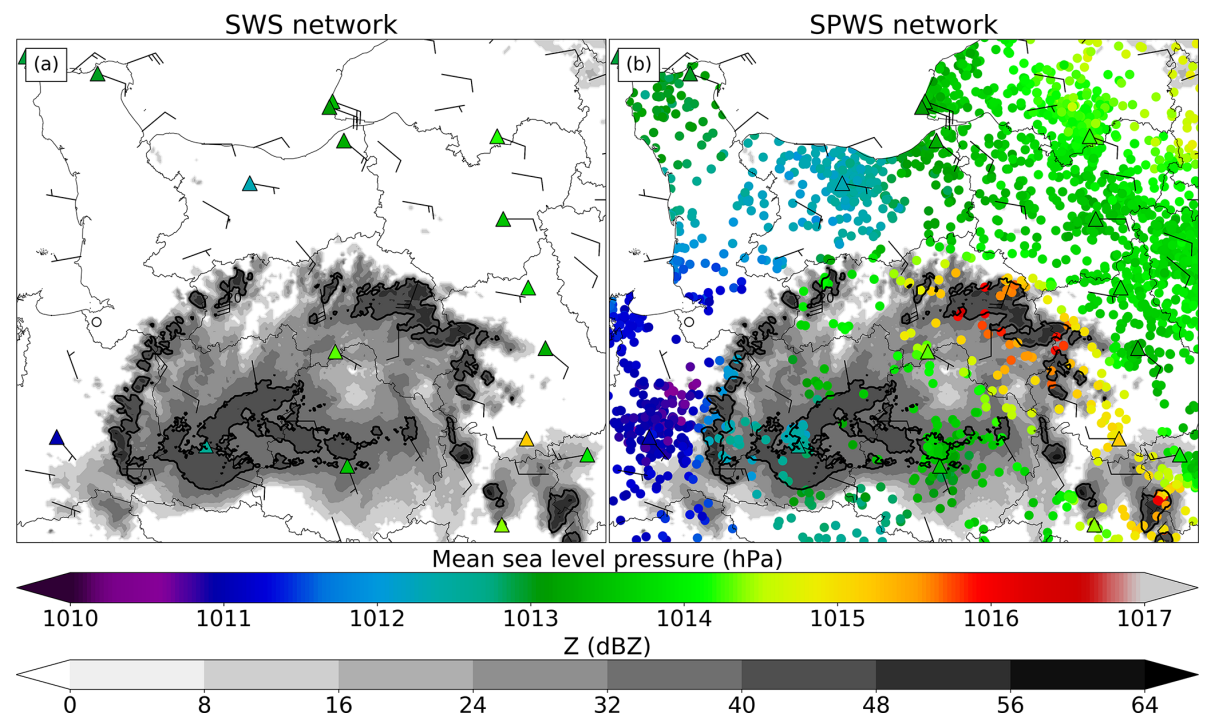

Figure 10. MSLP observations of (a) SWS network and (b) SPWS network at 18:15 UTC on 26 May. SWSs are indicated by coloured triangles with black contours and PWSs by coloured circles. The instantaneous wind gust is shown with barbs. Base reflectivity $(Z)$ in grey colours indicates thunderstorm activity and location. Reflectivities over $40 \mathrm{dBZ}$ are illustrated with bold black contours.

Table 5. Statistics of the LOOCV performed on SWS and SPWS observations of MSLP and validated on SWS observations for each case study. The evolution (in \%) is relative to the RMSE of SWS observations.

\begin{tabular}{|c|c|c|c|c|c|c|c|c|c|}
\hline \multirow{2}{*}{\multicolumn{2}{|c|}{$\begin{array}{c}\text { Case study } \\
\text { Network }\end{array}$}} & \multicolumn{2}{|c|}{26 May 2018} & \multicolumn{2}{|c|}{4 July 2018} & \multicolumn{2}{|c|}{15 July 2018} & \multicolumn{2}{|c|}{28 August 2018} \\
\hline & & SWS & SPWS & SWS & SPWS & SWS & SPWS & SWS & SPWS \\
\hline \multirow{2}{*}{ MSLP error $(\mathrm{hPa})$} & Median & 0.012 & -0.001 & 0.015 & -0.002 & 0.030 & -0.002 & 0.048 & 0.002 \\
\hline & $\begin{array}{l}\text { RMS } \\
\% \text { of evolution }\end{array}$ & 0.404 & $\begin{array}{l}0.099 \\
-7 \%\end{array}$ & 0.702 & $\begin{array}{r}0.187 \\
-73 \%\end{array}$ & 0.449 & $\begin{array}{r}0.104 \\
-77 \%\end{array}$ & 0.611 & $\begin{array}{r}0.151 \\
-75 \%\end{array}$ \\
\hline
\end{tabular}

over the four cases with the SPWS network compared to the SWS network.

\subsection{Sensitivity to the gridding method}

To study the sensitivity to the gridding method, we slightly modified the gridding method for the 26 May case. The power factor of the IDW was set to 1 instead of 2 . We observe little sensitivity to the change of the power factor. With a power factor of 1 (respectively 2), for SPWS the MSLP RMSE equals $0.118 \mathrm{hPa}(0.099 \mathrm{hPa})$, the temperature RMSE equals $0.877^{\circ} \mathrm{C}\left(0.889^{\circ} \mathrm{C}\right)$ and the relative-humidity RMSE equals $5.480 \%$ (5.375\%). Decreases in RMSE reach $70 \%(75 \%)$ in MSLP, $16 \%$ (16\%) in temperature and $17 \%$ $(21 \%)$ in relative humidity with SPWS compared to SWS.

\section{Results for selected convective cases}

In the following section, comparisons are made between SWS and SPWS networks by showing observed values at station locations or by comparing SWS and SPWS analyses.

\subsection{Contribution of PWSs to MSLP analyses}

\subsubsection{May 2018}

At 12:45 UTC on 26 May 2018, a squall line was located over the south-west of France. The MSLP field of SWS analysis (Fig. 11a) exhibits a single pressure high, reaching $1014.9 \mathrm{hPa}$, in the western part of the MCS, south of the highest reflectivities. It does not show significant pressure perturbations or strong pressure gradients in the eastern part of the MCS. In SPWS analysis (Fig. 11b), a crescent-shaped pressure high associated with the system is identified in MSLP, reaching 1015.0 to $1015.5 \mathrm{hPa}$, especially near and under the highest reflectivities in the convective part of the storm. A MSLP low is located at the rear of the stratiform part. Along the strong pressure gradients revealed by the SPWS network, high wind gusts of $19 \mathrm{~m} \mathrm{~s}^{-1}$ at 12:10 UTC and $25 \mathrm{~m} \mathrm{~s}^{-1}$ at 12:38 UTC were observed in the eastern part of the MCS. The MSLP field agreeing the most with MSLP anomalies described by the theory of squall lines (Johnson and Hamilton, 1988; Haertel and Johnson, 2000) is found in SPWS analysis. SPWS analysis is also more coherent with surface wind ob- 


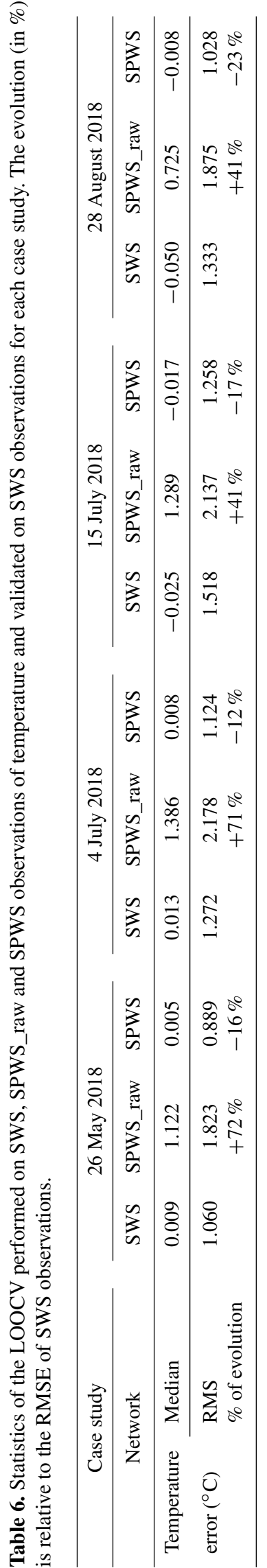

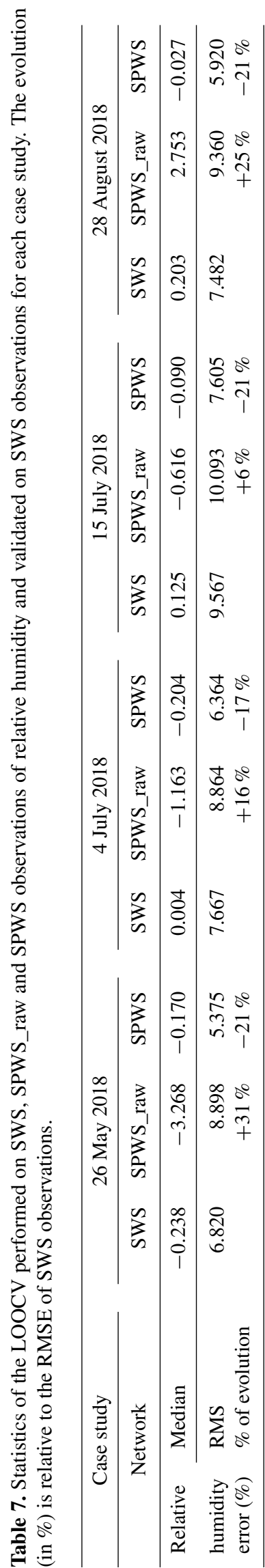

Nat. Hazards Earth Syst. Sci., 20, 299-322, 2020 


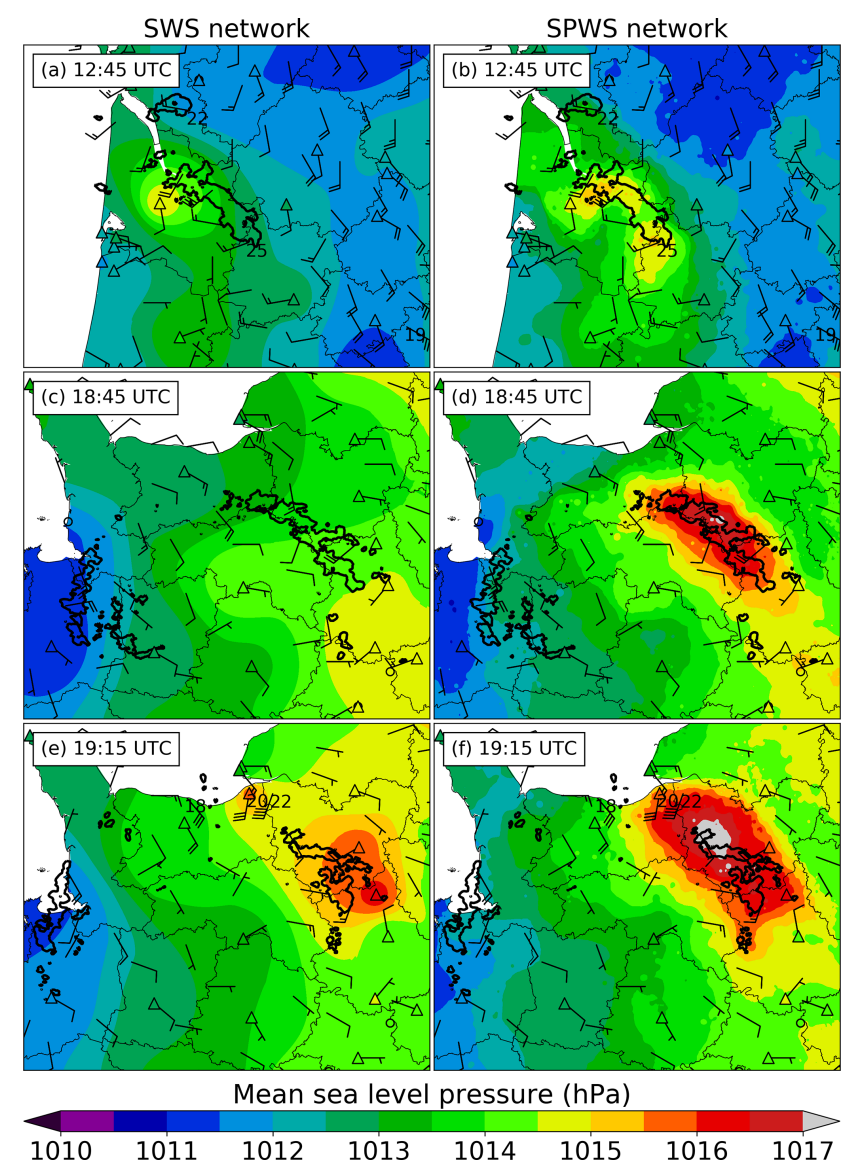

Figure 11. MSLP (a, c, e) SWS analyses and (b, d, f) SPWS analyses at (a, b) 12:45 UTC, (c, d) 18:45 UTC and (e, f) 19:15 UTC on 26 May. Reflectivities over $40 \mathrm{dBZ}$ are illustrated with bold black contours. SWS MSLP measurements are shown by coloured triangles with black contours. The instantaneous wind gust is shown with barbs, and the highest gust during the last $10 \mathrm{~min}$ over $17 \mathrm{~m} \mathrm{~s}^{-1}$ is annotated nearby.

servations than SWS analysis. A rise in MSLP under the supercell evolving ahead of the squall line is also exhibited by the SPWS analysis but is not observed in the SWS analysis, whereas a MSLP rise is usually observed under supercellular storms (Clark et al., 2018). Effects of this cell near the ground are confirmed by a nearby SWS which recorded a $22 \mathrm{~m} \mathrm{~s}^{-1}$ gust. An interesting MSLP feature is shown by SPWS analysis in this case: the MSLP field exhibits a crescent-shaped structure after 12:25 UTC, whereas the same structure is observed in reflectivity only after 13:00 UTC. The feature is observed just before the squall line evolve in a bow echo.

At 18:45 UTC, major differences between both analyses appear in MSLP. A surge in pressure associated with the bow echo is not visible in the SWS analysis (Fig. 11c), while the SPWS analysis shows it (Fig. 11d). At the surface high winds were observed: a SWS recorded a $20 \mathrm{~m} \mathrm{~s}^{-1}$ wind gust under the gust front at 18:48 UTC. Moreover, the high exhibited by the SPWS analysis is collocated with reflectivities over
$40 \mathrm{dBZ}$, indicating the location of thunderstorm cores. These clues, associated with the brutal increase in MSLP observed further by SWSs, agree with the presence of a MSLP high, absent of the SWS analysis.

At 19:15 UTC (Figs. 11e and f), the bow echo was over Normandy. SPWS analysis exhibits a pressure surge associated with the convective system with strong gradients of MSLP, especially in the part of the bow echo perpendicular to the propagation direction. This feature is coherent with the 18:45 UTC SPWS analysis and confirmed by a SWS on its path: it recorded a surge in MSLP reaching $1.5 \mathrm{hPa}$ in $10 \mathrm{~min}$ and $2.8 \mathrm{hPa}$ in $1 \mathrm{~h}$. The MSLP pressure front observed in the SPWS analysis is only partially seen by the SWS analysis: the SWS analysis exhibits independent MSLP surges and misses the MSLP maximum exhibited by the SPWS analysis. Moreover, at the same time, the radar network observed a decrease in reflectivities, especially in the northern part of the MCS, indicating a decay of the convective activity. However, near the surface, the SPWS analysis does not exhibit the vanishing of the MSLP high associated with the gust front. This decay is also not observed in surface winds: high wind gusts collocated and temporally synchronized with the gust front described by SPWS analyses were still observed. Gusts were recorded by four SWSs located in the north of Normandy, near the sea: $20 \mathrm{~m} \mathrm{~s}^{-1}$ at 19:11 UTC, $22 \mathrm{~m} \mathrm{~s}^{-1}$ at 19:13 UTC, $25 \mathrm{~m} \mathrm{~s}^{-1}$ at 19:25 UTC and $23 \mathrm{~m} \mathrm{~s}^{-1}$ at 19:27 UTC. Also, in the western part of the bow echo, where few thunderstorms remained, SPWS analysis shows weaker MSLP gradients than in the northern part of the bow echo. It is confirmed by SWSs that observed only moderate wind gusts.

The SWS network alone is not able to seize most MSLP features associated with this MCS, exhibited by the SPWS network. Wind speed, wind direction and SWS MSLP measurements are temporally and spatially coherent with the SPWS analyses, strengthening the confidence in this new analysis. In similar cases, the indication of remaining sharp MSLP gradients while radar reflectivities are decaying may help forecasters to keep warning about possible strong gusts near the surface, which seems relevant given the gusts observed in this case. During the bow echo life cycle, the SPWS analyses exhibit several pressure surges as described by Adams-Selin and Johnson (2010). The SPWS network may be used in further studies to compare these observed surges to their pressure surge-new bowing cycle theory.

\subsubsection{July 2018}

At 13:55 UTC on 4 July 2018, a well-formed squall line located near the mouth of the Garonne was moving towards the north-east. It generated a west-north-west $25 \mathrm{~m} \mathrm{~s}^{-1}$ gust in Bordeaux at 13:49 UTC and a west-south-west $18 \mathrm{~m} \mathrm{~s}^{-1}$ gust at 13:55 UTC in another SWS. The SWS analysis in Fig. 12a exhibits a MSLP high, but pressure gradients remain moderate: there is no indication of strengthening wind in the area. In the SPWS analysis visible in Fig. 12b, sharp gradients of 


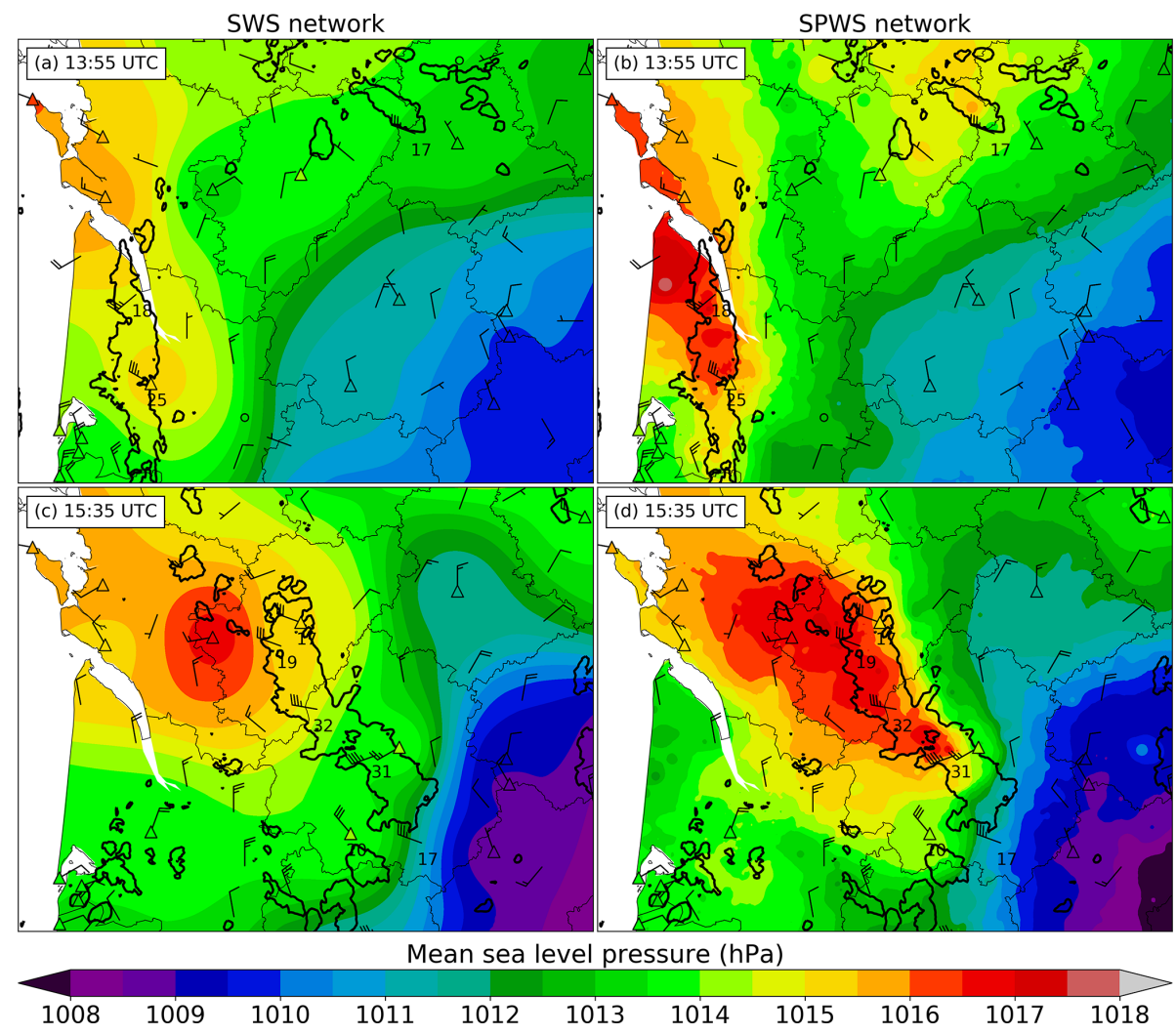

Figure 12. As in Fig. 11 but for the 4 July case. MSLP (a, c) SWS analyses and (b, d) SPWS analyses at (a, b) 13:55 UTC and (c, d) 15:35 UTC on 4 July.

MSLP appear at the location of the observed strong gusts. The SPWS analysis is coherent with the location of convective cells indicated by radars, with the surges in MSLP measured by SWSs and also with the wind gust directions almost perpendicular to MSLP gradients observed in the southern part of the line.

At 15:35 UTC, the SPWS analysis in Fig. 12d exhibits strong MSLP gradients, while SWS analysis in Fig. 12c shows weak gradients in comparison. These strong MSLP gradients are coherent with the position of the convective cells and the measured surface gust speeds. Gusts up to $32 \mathrm{~m} \mathrm{~s}^{-1}$ at $15: 26 \mathrm{UTC}$ and $31 \mathrm{~m} \mathrm{~s}^{-1}$ at $15: 32 \mathrm{UTC}$ are recorded by SWSs.

\subsubsection{August 2018}

At 19:05 UTC on 28 August 2018, a squall line was moving north-north-eastwards. Radar indicated a broad area of strong reflectivities over $40 \mathrm{dBZ}$. At the surface, high wind gusts were measured: $27 \mathrm{~m} \mathrm{~s}^{-1}$ near the centre of the line at 18:48 UTC, $31 \mathrm{~m} \mathrm{~s}^{-1}$ in its southern part at 18:58 UTC and $28 \mathrm{~m} \mathrm{~s}^{-1}$ in the northern part of the line at 19:04 UTC. These strong gusts were associated with jumps in MSLP: for example, in the northern SWS, the wind gust was preceded by a $2.8 \mathrm{hPa}$ surge in $4 \mathrm{~min}$ between 19:00 and 19:04 UTC.
These observed strong MSLP gradients at the gust front are in agreement with the sharper gradients shown by the SPWS analysis in Fig. 13b compared to the SWS analysis in Fig. 13a. Also, the location of the gust front, especially in its eastern part, is different between analyses: the SPWS analysis in Fig. 13b shows that the front has not reached two SWSs located south-east of the "32" number, whereas according to the SWS analysis in Fig. 13a, they were already affected by the front. SWS observations show weak gust speed, supporting the accuracy of the SPWS analysis.

At 20:35 UTC, SWSs observed strong gusts at the rear of the pressure front extending from north-north-west to southeast (Fig. 13c). The MSLP field of the SWS analysis does not explain such gusts, especially in the northern parts of the figure. The SPWS analysis in Fig. 13d reveals a MSLP surge under the northern convective line, which is missed by the SWS analysis. This high seems to cause the wind gusts between 19 and $23 \mathrm{~m} \mathrm{~s}^{-1}$ observed near the surface. The SWS analysis also indicates a lower surge in pressure at the south compared to SPWS analysis, probably because no SWS is located at its centre. The SPWS analysis provides insight about the convection organization because it shows that the convective line to the south and the one to the north are two independent squall lines: two pressure surges with separated wake lows at the rear are visible in the SPWS analysis, each cor- 


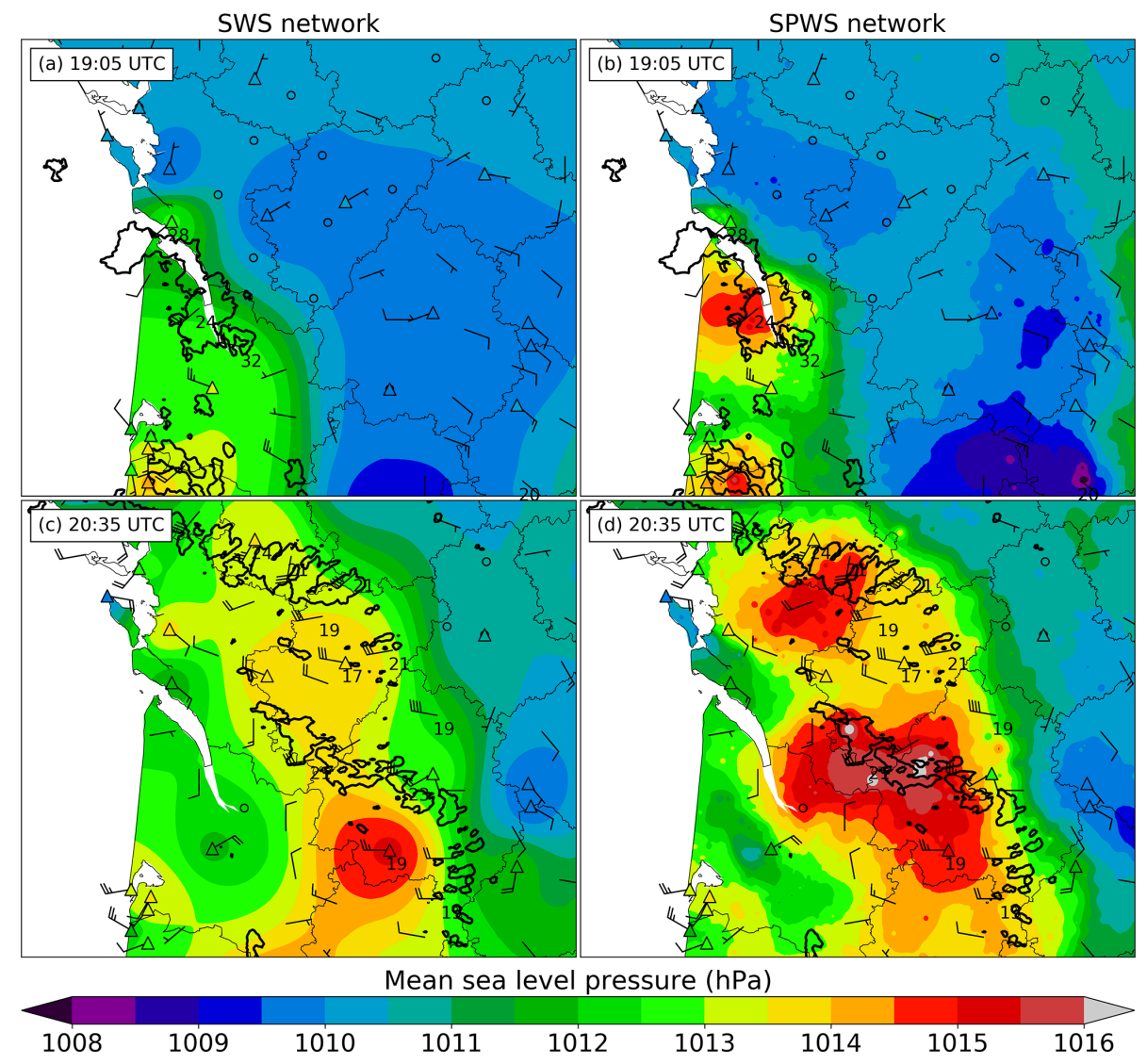

Figure 13. As in Fig. 11 but for the 28 August case. MSLP (a, c) SWS analyses and (b, d) SPWS analyses at (a, b) 19:05 UTC and (c, d) 20:05 UTC on 28 August.

responding to the theoretical structure of a squall line (Johnson and Hamilton, 1988). Even if their gust fronts merged in some areas, which triggered the formation of scattered cells between them, the pressure field and the direction of the main cells indicate that these two squall lines do not merge. The independence of the two lines is unclear with the SWS analysis in MSLP or with radar reflectivities. The independence of these two squall lines seems to be accurate because afterwards, according to radar reflectivities, the convective cells associated with the two MCS followed slightly different directions.

\subsection{Contribution of PWSs to temperature and humidity analyses}

The contribution of PWSs in two situations is shown. Measurements of surface pressure, temperature and relative humidity of SPWS network allow computing derived quantities such as virtual temperature, $T_{\mathrm{v}}$, the temperature of a dry air parcel which has the same density as the humid air considered, and the virtual potential temperature associated, $\theta_{\mathrm{v}}$, which is related to buoyancy and is identified as pertinent to track cold pools (e.g. Drager and Van den Heever, 2017). $\theta_{\mathrm{v}}$ is computed as follows:
$\theta_{\mathrm{v}}=T_{\mathrm{v}}\left(\frac{P_{0}}{P}\right)^{\frac{R_{0}}{M c_{\mathrm{p}}}}$,

with $P, M$ and $R_{0}$ being defined in Eq. (1); $T_{\mathrm{v}}$ being defined in Eq. (3); $P_{0}=1000 \mathrm{hPa}$ being the standard reference pressure; and $c_{\mathrm{p}}=\frac{7}{2} \frac{R_{0}}{M}$ being the specific heat capacity at a constant pressure.

\subsubsection{July 2018}

In the morning of 4 July 2018 , before the line studied in Sect. 6.1.2 affected the Bordeaux region, isolated storms formed over the south-west of France and moved northnorth-eastwards. At 12:55 UTC, a cluster of convective cells was seen by radar (Fig. 14a and b). The storm identified as a supercell, south-east of this cluster, produced tennis-ballsized hail a few minutes later. With the SPWS network, a temperature drop of about $6^{\circ} \mathrm{C}$ in $10 \mathrm{~min}$ under this cell and a rapid rise in relative humidity are observed. This is confirmed by a SWS which was on the path of this convective cell a few minutes later: the temperature dropped from 23.9 to $17.4{ }^{\circ} \mathrm{C}$, and relative humidity rose from $67 \%$ to $94 \%$ in $30 \mathrm{~min}$. In the upper-right part of the Fig. 14b, a storm crossed the east- 


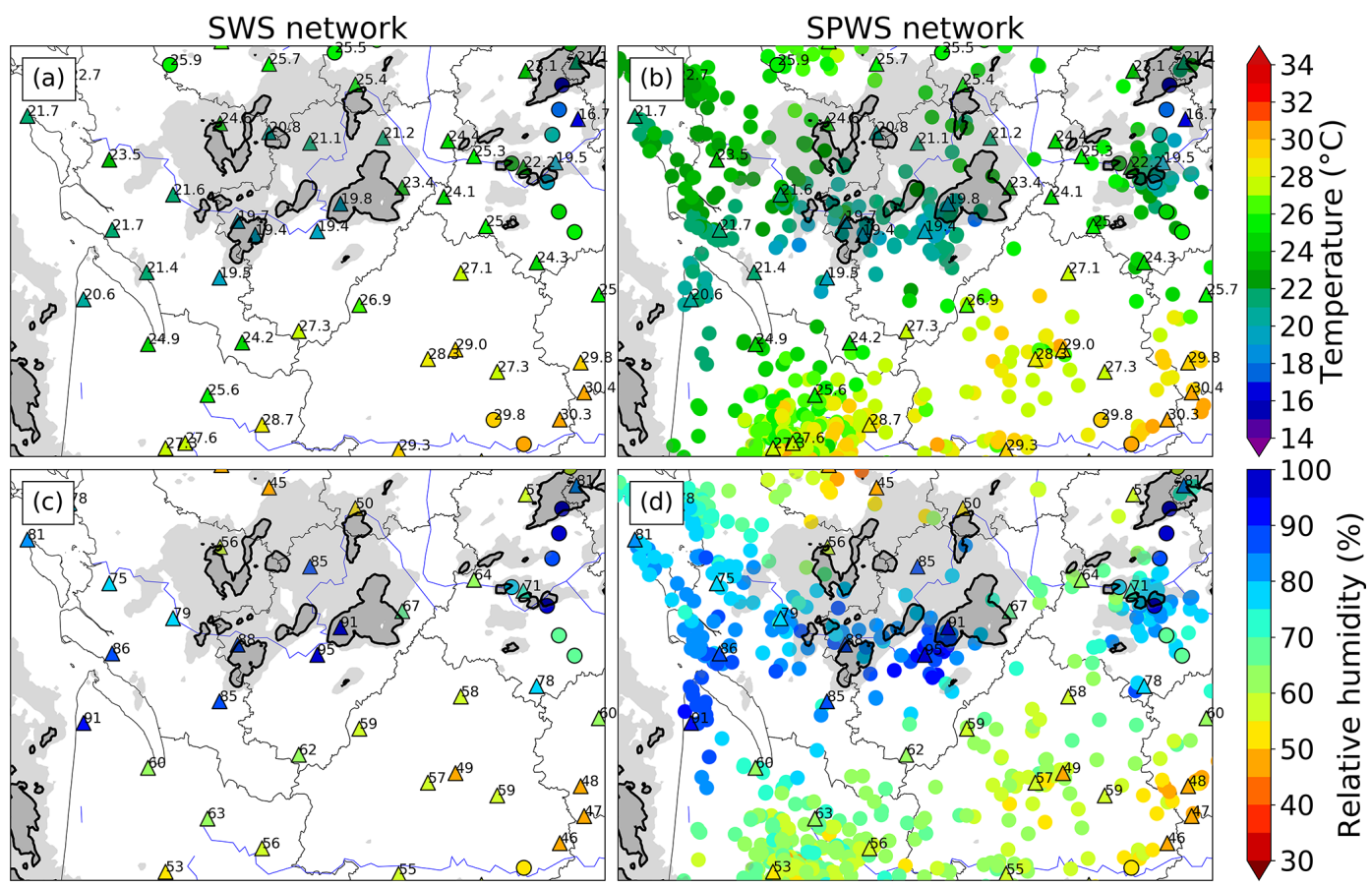

Figure 14. Observations of (a, b) temperature and (c, d) relative humidity at 12:55 UTC on 4 July with (a, c) SWS network and (b, d) SPWS network. SWS measurements are shown by coloured triangles with black contours. Additional 6 min time steps stations are circled in black with values, and road weather stations are only circled in black. Reflectivities $>18 \mathrm{dBZ}$ are light grey, and reflectivities $>40 \mathrm{dBZ}$ are grey with black contours.

ern part of the city of Limoges, where the spatial density of PWSs is high. The path of the cell is visible in temperature and relative humidity with more details with SPWSs than with SWSs only. The SWS located west of Limoges measured a $71 \%$ relative humidity, while several PWSs, located closer to the path of the cell, exceeded $80 \%$, values coherent with road station measurements of about $85 \%$ to $95 \%$. Also near the mouth of the Garonne, at the left of Fig. 14d, PWSs indicate high relative humidity between $70 \%$ and $90 \%$ that disagrees with a SWS measured value of $60 \%$. The analysis of radar reflectivities indicates that two storms concerned this area, but the SWS was not directly reached by one of them. In this case, the higher density of PWSs gives fine details of features in temperature and humidity associated with deep convection.

Later this day, isolated storms also formed before the arrival of a squall line over the west of the Massif Central mountains. One in particular created a powerful cold pool: temperature dropped by $15.1^{\circ} \mathrm{C}$ and relative humidity increased by $61 \%$ in $110 \mathrm{~min}$ at a SWS located near the centre of it. At 15:35 UTC, additional weather stations not used to build analyses of Fig. 15a and b, measuring only temperature with a 6 min time step (measured at 15:36 UTC), were added to the figures to assess the quality of the temperature fields. Main differences in temperature are observed in the warm area between the cold pool and the left of the figures. Two additional weather stations agree with the increase in temperature proposed in this area by the SPWS analysis in Fig. 15b, especially north-west of the cold pool. A small decrease in temperature is also shown by the SPWS analysis south-west of the figure associated with a small convective cell but is not shown by the SWS analysis. In terms of relative humidity, differences are also visible between Fig. 15c and d. In four areas, east, south-south-east, south-west and west-south-west, of the central cold pool, relative humidity is higher in SPWS analysis than in SWS analysis. After looking at the reflectivity field, the observed increases are temporally and spatially consistent with the passage of isolated convective cells over these four areas.

In this case, the development of a cold pool that extended over time in all directions is observed. The extension of the cold pool towards the south, east and west initiated deep convection in these directions between 15:35 and 15:55 UTC (Fig. 16). South of the cold pool, small cells advected in a south-westerly flux brutally strengthened near the coldpool boundary. Two PWSs, located in this area, observed the southern boundary of the cold pool: SPWS analyses between 15:25 and 15:45 UTC show the $\theta_{\mathrm{v}}=31^{\circ} \mathrm{C}$ limit extending southwards faster than in SWS analyses, near the location where convective cells strengthened. Fine-scale observations of cold-pool boundaries may help to identify locations where lifting is favoured. West of this isolated cold pool, secondary convective initiation was observed before the MCS cold pool located to the left of the figure and the iso- 

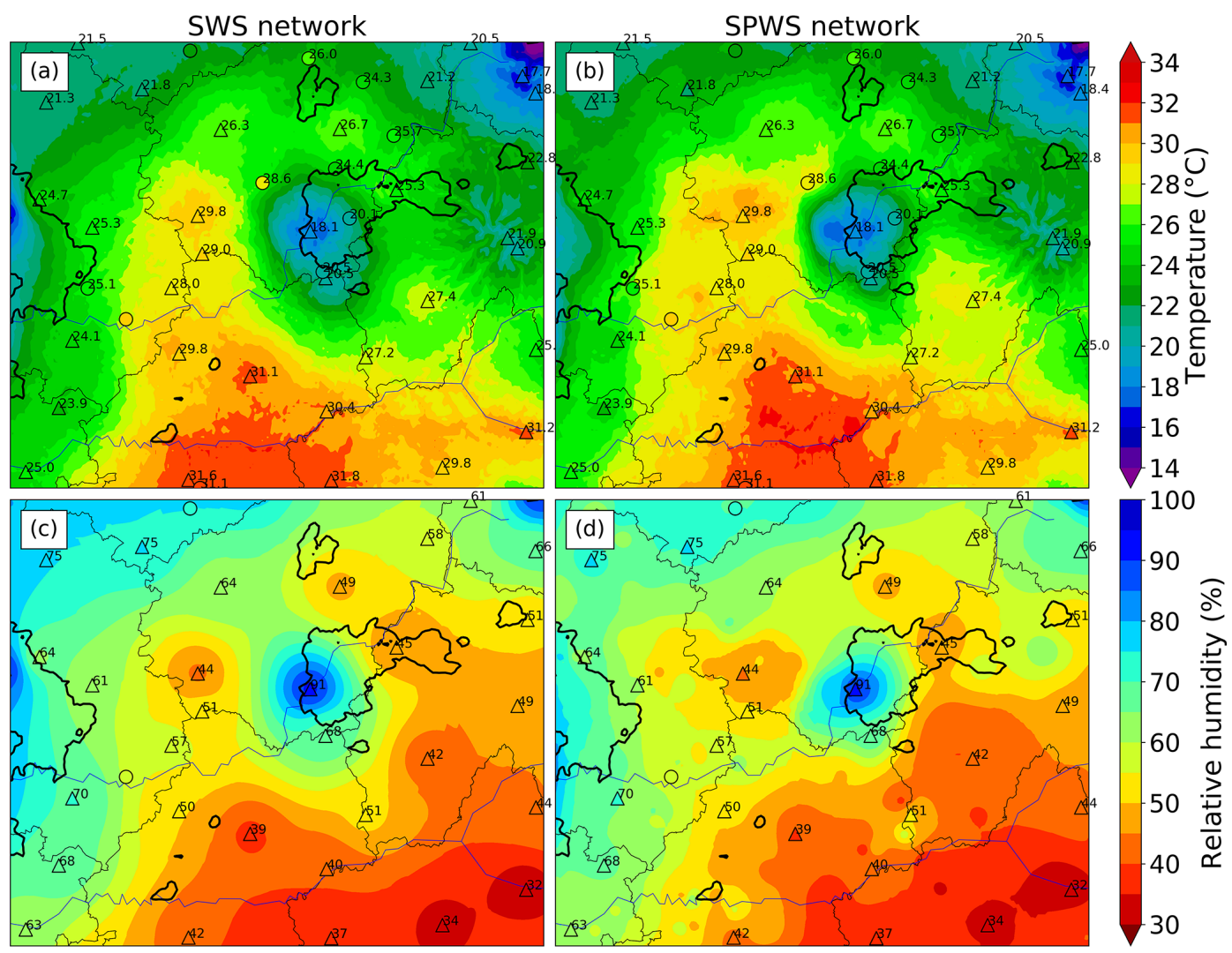

Figure 15. (a, b) Temperature and (c, d) relative-humidity (a, c) SWS analyses and (b, d) SPWS analyses at 15:35 UTC on 4 July. Station measurements are as in Fig. 14. Reflectivities over $40 \mathrm{dBZ}$ are illustrated with bold black contours.

lated cold pool merged. Areas where convective storms were triggered have a higher $\theta_{\mathrm{v}}$ in SPWS analysis (Fig. 16f) than in SWS analysis (Fig. 16e). At 16:15 UTC, the main difference between both analyses concerns a warm zone between the MCS cold pool to the west and the isolated cold pool. Warm conditions with temperatures around $24^{\circ} \mathrm{C}$ are observed by SPWS network, while the SWS network indicates temperatures between 20 and $22^{\circ} \mathrm{C}$. These higher temperatures are confirmed by two additional weather stations indicating temperatures 2 to $4{ }^{\circ} \mathrm{C}$ higher than the temperature given by SWS analysis. These differences in temperature mainly explain the differences in potential virtual temperatures observed in this area between Fig. 16e and f: $\theta_{\mathrm{v}}$ values between 26 and $30^{\circ} \mathrm{C}$ are indicated by SPWS analysis against 24 to $26^{\circ} \mathrm{C}$ in SWS analysis.

\subsubsection{July 2018}

On 15 July 2018, an isolated thunderstorm formed at the south-east of Arcachon Bay (Fig. 17), where converging winds due to a sea breeze were observed. A SWS was located near the initiation point and measured warm temperatures around $32^{\circ} \mathrm{C}$ before the initiation and relative humidity around $48 \%$. North of this station, other inland SWSs with comparable temperatures measured lower relative hu- midity between $34 \%$ to $38 \%$ at the same time. Steep gradients of $2 \mathrm{~m}$ temperature and $2 \mathrm{~m}$ relative humidity were observed, with a $5{ }^{\circ} \mathrm{C}$ temperature change within $40 \mathrm{~km}$ and a $22 \%$ relative-humidity change within $30 \mathrm{~km}$. The thunderstorm moved north-eastwards and triggered the initiation of few convective towers. The cluster of convective towers then split into two main cells, one headed east and the other north (Fig. 17). At the surface, both cells induced drops in temperature and rises in relative humidity. However, at 14:45 UTC, no SWS was directly under the path of the cells: only a small decrease in temperature and small increase in relative humidity were observed at long range. At the same time, several PWSs recorded drops in temperature and strong increases in relative humidity associated to radar reflectivities above $40 \mathrm{dBZ}$. At the next time steps, several SWSs detected features of similar or higher amplitude that supported the consistency of PWS observations. In this case, adding PWSs gives insight into the extension of the cold pool associated with thunderstorms and confirms that precipitation are reaching the surface. This leads to differences between SWS and SPWS analyses up to $6^{\circ} \mathrm{C}$ in temperature, $30 \%$ in relative humidity and $8^{\circ} \mathrm{C}$ in virtual potential temperature in areas affected by thunderstorms. The increased spatial density contributes to a finer mapping of areas that were cooled or, on 
SWS network
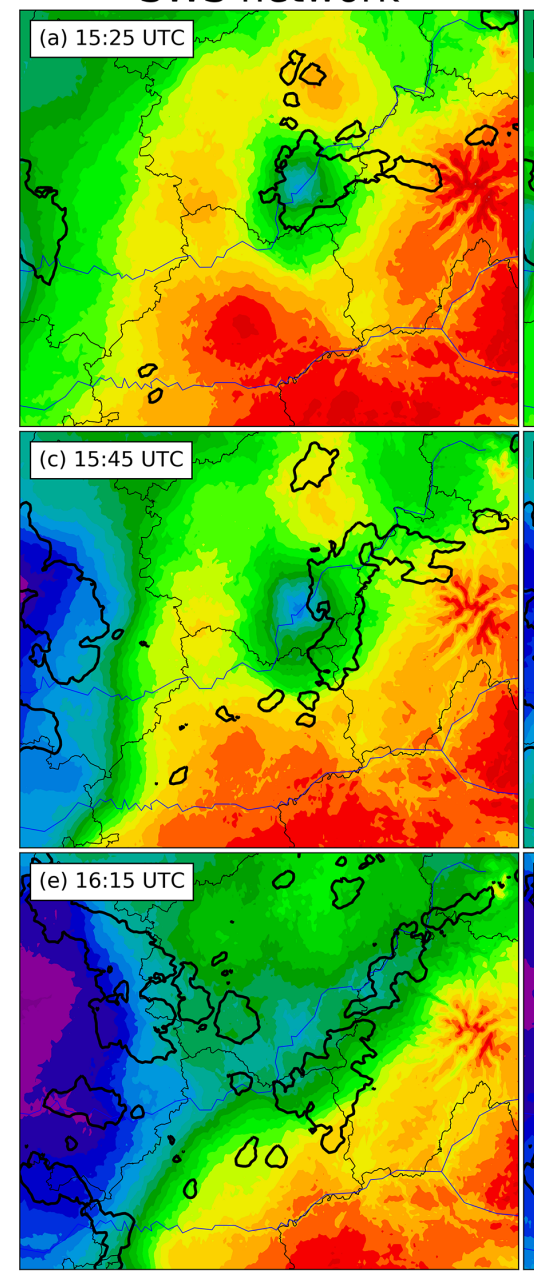

\section{SPWS network}
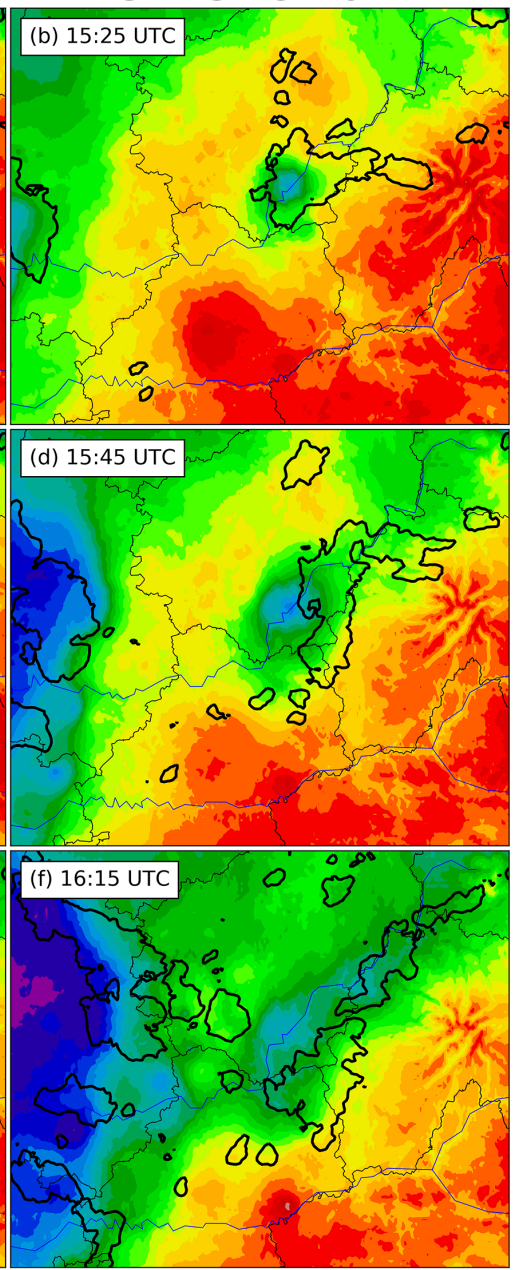

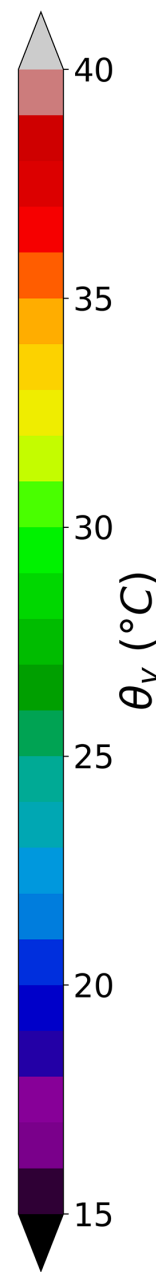

Figure 16. $\theta_{\mathrm{v}}$ (a, c, e) SWS analyses and (b, d, f) SPWS analyses at (a, b) 15:25 UTC, (c, d) 15:45 UTC and (e, f) 16:15 UTC on 4 July. Reflectivities over $40 \mathrm{dBZ}$ are illustrated with bold black contours.

the contrary, areas where convective cells have not cooled the atmosphere near the ground, which may be the location of further convective initiations.

\section{Conclusions}

Some PWS networks now sample the atmosphere at high spatial and temporal resolution: the Netatmo network, on which this study is focused, constitutes a network of weather stations of identical sensors with unprecedented density available in near-real time, with a minimum 5 min temporal resolution.

Adding raw PWS data in observed surface analyses strongly deteriorates the RMSE calculated by LOOCV in comparison with using only SWS analyses. This increased the RMSE $\mathrm{LOOCV}_{\text {from }} 41 \%$ to $72 \%$ in temperature and from $6 \%$ to $31 \%$ in relative humidity depending on the case, showing the negative contribution of PWSs if they are not properly preprocessed and quality-controlled.

An automatic processing including a quality control was designed and based on comparison with SWS analyses over short temporal windows. Median systematic errors are computed and corrected at first for all parameters. Simple quality checks with four steps in pressure, and only three in temperature and humidity, were designed. In terms of temperature and humidity, the main step eliminates PWS time series with departures that are too high when compared to SWS analyses in RMSE. The RMSE threshold is automatically chosen by minimizing a RMSE $E_{\mathrm{LOOCV}}$, taking the SWS network as the validation dataset. With respect to pressure, an algorithm performing, at each step, a LOOCV taking all stations as the validation dataset was developed. The PWS providing the highest $\mathrm{RMSE}_{\mathrm{LOOCV}, k}$ is eliminated at each step. The algorithm stops when the first local minimum in RMSE $\mathrm{LOOCV}_{\text {is ob- }}$ tained. Over the four case studies, the mean number of PWS observations kept after processing is $91 \% \pm 3 \%$ in MSLP, 

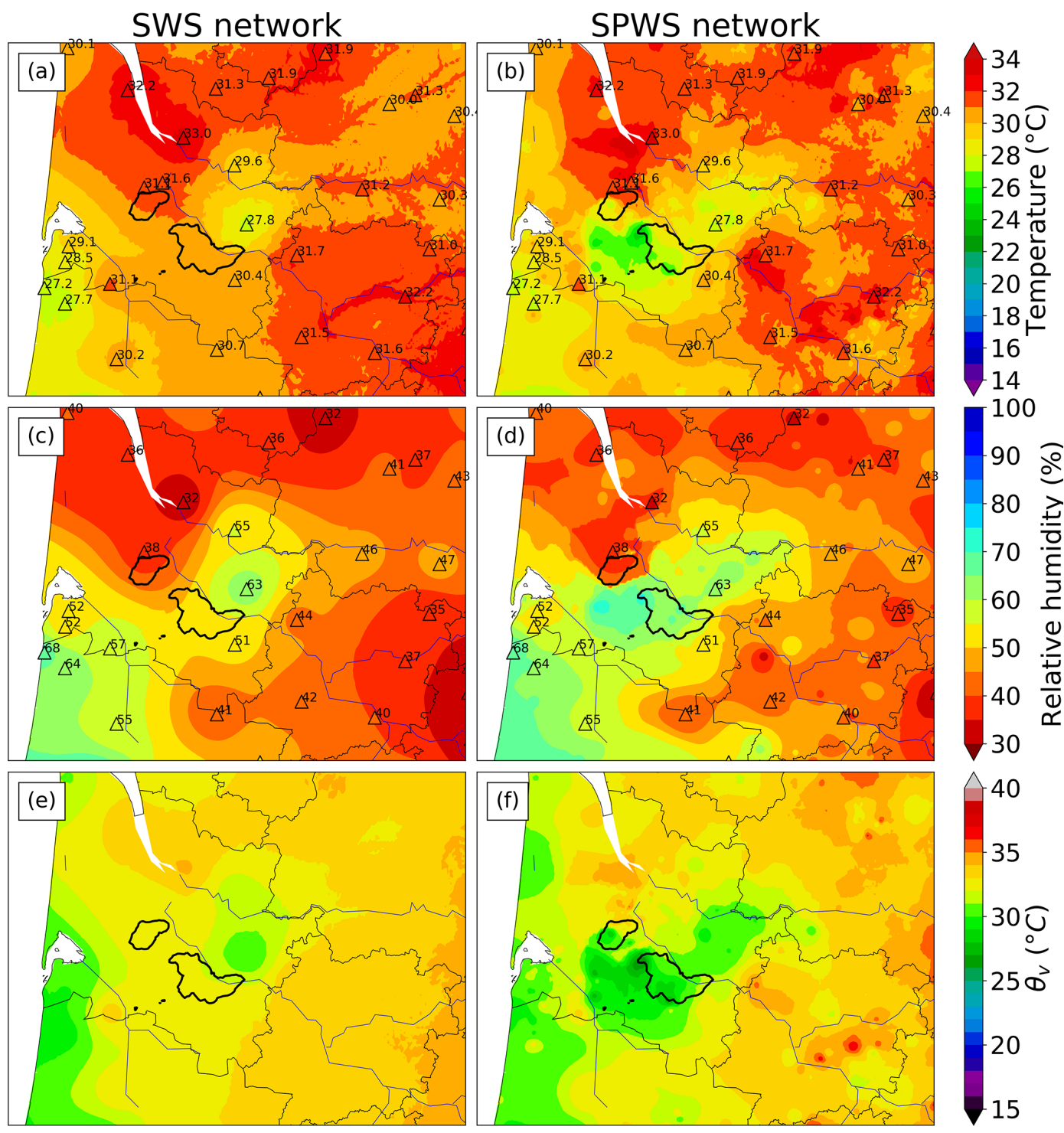

Figure 17. (a, b) Temperature, (c, d) relative-humidity and (e, f) virtual potential temperature (a, c, e) SWS analyses and (b, d, f) SPWS analyses at 14:45 UTC on 15 July. Station measurements are as in Fig. 14. Reflectivities over 40 dBZ are illustrated with bold black contours.

$37 \% \pm 7 \%$ in temperature and $39 \% \pm 12 \%$ in relative humidity. On average, the number of available observations is multiplied by 134 in MSLP, by 11 in temperature and by 14 in relative humidity.

A LOOCV was performed in several convective cases to validate the method on the SWS observations. Results over metropolitan France show a substantial decrease in the RMSE $_{L O O C V}$ between $73 \%$ and $77 \%$ in MSLP. Decreases in RMSE $_{\mathrm{LOOCV}}$ are also observed in temperature between $12 \%$ and $23 \%$, while the decrease in relative humidity reaches $17 \%$ to $21 \%$. These scores quantitatively show that adding PWSs to SWSs improves the accuracy of surface analyses, especially in MSLP.

Qualitatively, fine-scale structures partly or not seen by SWS network only showed up in MSLP, temperature and humidity when PWS and SWS networks were combined in several case studies. In terms of MSLP, pressure surges accompanying squall lines were observed as well as wake lows at the rear of these lines. Pressure surges accompanying individual cells were also observed. A crescent-shaped MSLP structure was observed approximately $1 \mathrm{~h}$ prior to the transition of a squall line in a bow echo. Also, a gust front still producing wind gusts up to $25 \mathrm{~m} \mathrm{~s}^{-1}$ was detected and its movement tracked while its associated convective system exhibited rapid decay in radar reflectivities. These structures were consistent with the movement of storm systems detected by radar and with observed variations in MSLP or wind speed at SWSs locations. All these structures observed with the SPWS network were only partly visible or not visible at all with SWS observations only. 
In temperature and humidity, temperature drops and humidity surges accompanying most of the cells were observed, giving a storm signature at the ground in temperature and humidity. The virtual potential temperature $\theta_{\mathrm{v}}$ derived from surface observations was spatialized at an unprecedented spatial resolution thanks to PWS contributions. In two case studies, cold-pool propagation and secondary convective initiation over areas of high virtual potential temperatures, i.e. favourable locations for near-surface parcel lifting, were observed. Future work will focus on using these observations for the validation of fine-scale numerical simulations of convective cases. The goal is to figure out whether these simulations reproduce all the phenomena observed by these PWSs and investigate the potential differences as a preparatory work before a possible assimilation of these new data. Future work may also include the development of an operational tool to display these PWS measurements, especially to track convective structures, at a 5 min temporal resolution if possible. Points as early discrimination between surfacebased and elevated convection, as well as favoured locations for convective initiation or secondary cell development, already highlighted by Clark et al. (2018), may also be investigated.

Data availability. SWS and radar data are provided by and property of Météo-France. PWS data are provided by and property of Netatmo. All datasets can be provided on demand by the corresponding author only for research purposes.

Author contributions. This work was carried out by MM as part of his $\mathrm{PhD}$ thesis under the supervision of OC. MM and OC collaborated, interpreted the results and wrote the paper.

Competing interests. The authors declare that they have no conflict of interest.

Acknowledgements. We wish to thank the Météo-France Direction des Systèmes d'Observations for the field tests of the PWSs they performed and for all datasets provided. We acknowledge the use of imagery from the NASA Worldview application (https://worldview.earthdata.nasa.gov, last access: 15 January 2020), part of the NASA Earth Observing System Data and Information System (EOSDIS). This work was supported by the French National programme LEFE (Les Enveloppes Fluides et l'Environnement; project ASMA). The authors would also like to thank the two anonymous referees for their comments that helped to significantly improve the quality of the article.

lefe
Review statement. This paper was edited by Vassiliki Kotroni and reviewed by two anonymous referees.

\section{References}

Adams-Selin, R. D. and Johnson, R. H.: Mesoscale Surface Pressure and Temperature Features Associated with Bow Echoes, Mon. Weather Rev., 138, 212-227, https://doi.org/10.1175/2009MWR2892.1, 2010.

Bell, S., Cornford, D., and Bastin, L.: The state of automated amateur weather observations, Weather, 68, 36-41, https://doi.org/10.1002/wea.1980, 2013.

Chapman, L., Bell, C., and Bell, S.: Can the crowdsourcing data paradigm take atmospheric science to a new level? A case study of the urban heat island of London quantified using Netatmo weather stations, Int. J. Climatol., 37, 3597-3605, https://doi.org/10.1002/joc.4940, 2017.

Clark, M. R.: An observational study of the exceptional 'Ottery St Mary' thunderstorm of 30 October 2008, Meteorol. Appl., 18, 137-154, https://doi.org/10.1002/met.187, 2011.

Clark, M. R., Webb, J. D. C., and Kirk, P. J.: Fine-scale analysis of a severe hailstorm using crowd-sourced and conventional observations, Meteorol. Appl., 25, 472-492, https://doi.org/10.1002/met.1715, 2018.

de Ruijter, T.: Altitude: querying SRTM data on the fly, available at: http://github.com/tomderuijter/altitude (last access: 15 January 2020), 2016.

de Vos, L. W., Leijnse, H., Overeem, A., and Uijlenhoet, R.: The potential of urban rainfall monitoring with crowdsourced automatic weather stations in Amsterdam, Hydrol. Earth Syst. Sci., 21, 765-777, https://doi.org/10.5194/hess-21-765-2017, 2017.

de Vos, L. W., Raupach, T. H., Leijnse, H., Overeem, A., Berne, A., and Uijlenhoet, R.: High-Resolution Simulation Study Exploring the Potential of Radars, Crowdsourced Personal Weather Stations, and Commercial Microwave Links to Monitor SmallScale Urban Rainfall, Water Resour. Res., 54, 10293-10312, https://doi.org/10.1029/2018WR023393, 2018.

de Vos, L. W., Leijnse, H., Overeem, A., and Uijlenhoet, R.: Quality Control for Crowdsourced Personal Weather Stations to Enable Operational Rainfall Monitoring, Geophys. Res. Lett., 46, 88208829, https://doi.org/10.1029/2019GL083731, 2019.

Drager, A. J. and Van den Heever, S. C.: Characterizing convective cold pools, J. Adv. Model. Earth Syst., 9, 1091-1115, https://doi.org/10.1002/2016MS000788, 2017.

Farr, T. G., Rosen, P. A., Caro, E., Crippen, R., Duren, R., Hensley, S., Kobrick, M., Paller, M., Rodriguez, E., Roth, L., Seal, D., Shaffer, S., Shimada, J., Umland, J., Werner, M., Oskin, M., Burbank, D., and Alsdorf, D.: The Shuttle Radar Topography Mission, Rev. Geophys., 45, RG2004, https://doi.org/10.1029/2005RG000183, 2007.

Figueras i Ventura, J. and Tabary, P.: The New French Operational Polarimetric Radar Rainfall Rate Product, J. Appl. Meteorol. Clim., 52, 1817-1835, https://doi.org/10.1175/JAMC-D-120179.1, 2013.

Fowle, M. A. and Roebber, P. J.: Short-Range (0-48 h) Numerical Prediction of Convective Occurrence, Mode, and Location, Weather Forecast., 18, 782-794, https://doi.org/10.1175/15200434(2003)018<0782:SHNPOC >2.0.CO;2, 2003. 
Garratt, J. R.: Some aspects of mesoscale pressure field analysis, Aust. Meteorol. Mag., 32, 115-122, 1984.

Gasperoni, N. A., Wang, X., Brewster, K. A., and Carr, F. H.: Assessing Impacts of the High-Frequency Assimilation of Surface Observations for the Forecast of Convection Initiation on 3 April 2014 within the Dallas-Fort Worth Test Bed, Mon. Weather Rev., 146, 3845-3872, https://doi.org/10.1175/MWRD-18-0177.1, 2018.

Haertel, P. T. and Johnson, R. H.: The Linear Dynamics of Squall Line Mesohighs and Wake Lows, J. Atmos. Sci., 57, 93-107, https://doi.org/10.1175/15200469(2000)057<0093:TLDOSL>2.0.CO;2, 2000.

Hintz, K. S., Vedel, H., and Kaas, E.: Collecting and processing of barometric data from smartphones for potential use in numerical weather prediction data assimilation, Meteorol. Appl., 26, 733746, https://doi.org/10.1002/met.1805, 2019.

Johnson, R. H. and Hamilton, P. J.: The Relationship of Surface Pressure Features to the Precipitation and Airflow Structure of an Intense Midlatitude Squall Line, Mon. Weather Rev., 116, 1444-1473, https://doi.org/10.1175/15200493(1988)116<1444:TROSPF>2.0.CO;2, 1988.

Madaus, L. E. and Hakim, G. J.: Observable Surface Anomalies Preceding Simulated Isolated Convective Initiation, Mon. Weather Rev., 144, 2265-2284, https://doi.org/10.1175/MWRD-15-0332.1, 2016.

Madaus, L. E. and Mass, C. F.: Evaluating Smartphone Pressure Observations for Mesoscale Analyses and Forecasts, Weather Forecast., 32, 511-531, https://doi.org/10.1175/WAF-D-16-0135.1, 2017.

Madaus, L. E., Hakim, G. J., and Mass, C. F.: Utility of Dense Pressure Observations for Improving Mesoscale Analyses and Forecasts, Mon. Weather Rev., 142, 2398-2413, https://doi.org/10.1175/MWR-D-13-00269.1, 2014.

Mahoney, W. P. and O'Sullivan, J. M.: Realizing the Potential of Vehicle-Based Observations, B. Am. Meteorol. Soc., 94, 10071018, https://doi.org/10.1175/BAMS-D-12-00044.1, 2013.

Mass, C. F. and Madaus, L. E.: Surface Pressure Observations from Smartphones: A Potential Revolution for High-Resolution Weather Prediction?, B. Am. Meteorol. Soc., 95, 1343-1349, https://doi.org/10.1175/BAMS-D-13-00188.1, 2014.

McNicholas, C. and Mass, C. F.: Smartphone Pressure Collection and Bias Correction Using Machine Learning, J. Atmos. Ocean. Tech., 35, 523-540, https://doi.org/10.1175/JTECH-D17-0096.1, 2018a.

McNicholas, C. and Mass, C. F.: Impacts of Assimilating Smartphone Pressure Observations on Forecast Skill during Two Case Studies in the Pacific Northwest, Weather Forecast., 33, 13751396, https://doi.org/10.1175/WAF-D-18-0085.1, 2018b.

Meier, F., Fenner, D., Grassmann, T., Otto, M., and Scherer, D.: Crowdsourcing air temperature from citizen weather stations for urban climate research, Urban Climate, 19, 170-191, https://doi.org/10.1016/j.uclim.2017.01.006, 2017.

Muller, C., Chapman, L., Johnston, S., Kidd, C., Illingworth, S., Foody, G., Overeem, A., and Leigh, R.: Crowdsourcing for climate and atmospheric sciences: current status and future potential, Int. J. Climatol., 35, 3185-3203, https://doi.org/10.1002/joc.4210, 2015.
Napoly, A., Grassmann, T., Meier, F., and Fenner, D.: Development and Application of a Statistically-Based Quality Control for Crowdsourced Air Temperature Data, Front. Earth Sci., 6, 118, https://doi.org/10.3389/feart.2018.00118, 2018.

Netatmo: Weather station specifications, available at: https: //www.netatmo.com/fr-fr/weather/weatherstation/specifications (last access: 15 January 2020), 2019.

Overeem, A., R. Robinson, J. C., Leijnse, H., Steeneveld, G. J., Horn, B. K., and Uijlenhoet, R.: Crowdsourcing urban air temperatures from smartphone battery temperatures, Geophys. Res. Lett., 40, 4081-4085, https://doi.org/10.1002/grl.50786, 2013.

Sanders, F. and Doswell, C. A.: A Case for Detailed Surface Analysis, B. Am. Meteorol. Soc., 76, 505-522, https://doi.org/10.1175/15200477(1995)076<0505:ACFDSA>2.0.CO;2, 1995.

Santurette, P. and Joly, A.: ANASYG/PRESYG, Météo-France's new graphical summary of the synoptic situation, Meteorol. Appl., 9, 129-154, https://doi.org/10.1017/S1350482702002013, 2002.

Snook, N., Xue, M., and Jung, Y.: Multiscale EnKF Assimilation of Radar and Conventional Observations and Ensemble Forecasting for a Tornadic Mesoscale Convective System, Mon. Weather Rev., 143, 1035-1057, https://doi.org/10.1175/MWRD-13-00262.1, 2015.

Sobash, R. A. and Stensrud, D. J.: Assimilating Surface Mesonet Observations with the EnKF to Improve Ensemble Forecasts of Convection Initiation on 29 May 2012, Mon. Weather Rev., 143, 3700-3725, https://doi.org/10.1175/MWR-D-14-00126.1, 2015.

Stensrud, D. J. and Fritsch, J. M.: Mesoscale Convective Systems in Weakly Forced Large-Scale Environments. Part III: Numerical Simulations and Implications for Operational Forecasting, Mon. Weather Rev., 122, 2084-2104, https://doi.org/10.1175/15200493(1994)122<2084:MCSIWF>2.0.CO;2, 1994.

Tardieu, J. and Leroy, M.: Radome, le réseau temps réel d'observation au sol de Météo-France, La Météorologie, 2, 4043, https://doi.org/10.4267/2042/36262, 2003.

Wakimoto, R. M. and Murphey, H. V.: Analysis of Convergence Boundaries Observed during IHOP_2002, Mon. Weather Rev., 138, 2737-2760, https://doi.org/10.1175/2010MWR3266.1, 2010.

Wilson, J. W. and Schreiber, W. E.: Initiation of Convective Storms at Radar-Observed Boundary-Layer Convergence Lines, Mon. Weather Rev., 114, 2516-2536, https://doi.org/10.1175/15200493(1986)114<2516:IOCSAR>2.0.CO;2, 1986.

Wolters, D. and Brandsma, T.: Estimating the Urban Heat Island in Residential Areas in the Netherlands Using Observations by Weather Amateurs, J. Appl. Meteorol. Clim., 51, 711-721, https://doi.org/10.1175/JAMC-D-11-0135.1, 2012.

World Meteorological Organization: Guide to Meteorological Instruments and Methods of Observation, WMO-No. 8, available at: https://library.wmo.int/doc_num.php?explnum_id=4147 (last access: 15 January 2020), 2014. 